Article

\title{
Syntheses and Glycosidase Inhibitory Activities, and in Silico Docking Studies of Pericosine E Analogs Methoxy-Substituted at C6
}

\author{
Yoshihide Usami ${ }^{1}$ **1) , Megumi Higuchi ${ }^{1}$, Koji Mizuki ${ }^{1}$, Mizuki Yamamoto ${ }^{1}$, Mao Kanki ${ }^{1}$, \\ Chika Nakasone ${ }^{1}$, Yuya Sugimoto ${ }^{1}$, Makio Shibano ${ }^{2}$, Yoshihiro Uesawa $\left.^{3}{ }^{(}\right)$, Junko Nagai ${ }^{3}(\mathbb{D}$, \\ Hiroki Yoneyama ${ }^{1}$ and Shinya Harusawa ${ }^{1}$ \\ 1 Department of Pharmaceutical Organic Chemistry, Osaka University of Pharmaceutical Sciences, \\ Nasahara 4-20-1, Takatsuki, Osaka 569-1094, Japan; e14537@gap.oups.ac.jp (M.H.); \\ e12007@gap.oups.ac.jp (K.M.); e13213@gap.oups.ac.jp (M.Y.); e15714@gap.oups.ac.jp (M.K.); \\ e11606@gap.oups.ac.jp (C.N.); e11605@gap.oups.ac.jp (Y.S.); yoneyama@gly.oups.ac.jp (H.Y.); \\ harusawa@gly.oups.ac.jp (S.H.) \\ 2 Department of Natural Products Research, Osaka University of Pharmaceutical Sciences, Nasahara 4-20-1, \\ Takatsuki, Osaka 569-1094, Japan; shibano@gly.oups.ac.jp \\ 3 Department of Medical Molecular Informatics, Meiji Pharmaceutical University, 2-522-1 Noshio, Kiyose, \\ Tokyo 204-8588, Japan; uesawa@my-pharm.ac.jp (Y.U.); nagai-j@my-pharm.ac.jp (J.N.) \\ * Correspondence: usami@gly.oups.ac.jp; Tel.: +81-796-90-1087; Fax: +81-796-90-1005
}

Received: 15 February 2020; Accepted: 17 April 2020; Published: 20 April 2020

\begin{abstract}
Inspired by the significant $\alpha$-glucosidase inhibitory activities of $(+)$ - and (-)-pericosine E, we herein designed and synthesized 16 analogs of these marine natural products bearing a methoxy group instead of a chlorine atom at C6. Four of these compounds exhibited moderate $\alpha$-glucosidase inhibitory activities, which were weaker than those of the corresponding chlorine-containing species. The four compounds could be prepared by coupling reactions utilizing the (-)-pericosine B moiety. An additional in silico docking simulation suggested that the reason of reduced activity of the C6-methoxylated analogs might be an absence of hydrogen bonding between a methoxy group with the surrounding amino acid residues in the active site in $\alpha$-glucosidase.
\end{abstract}

Keywords: pericosine E; marine natural product; C6-methoxy analogue; $\alpha$-glucosidase inhibitor; anti-diabetes drug; docking simulation

\section{Introduction}

Pericosines A-C and E (1-4) are marine natural products produced by the fungus Periconia byssoides OUPS-N133 derived from sea hare Aplysia kurodai (Figure 1) [1]. The unique carbasugar structures of these species and the significant antitumor activity of pericosine A have drawn increased attention to pericosines A-C (1-3) as synthetic targets and thus inspired numerous synthetic studies [2-9]. Natural pericosine $\mathrm{E}$ (4) deserves particular attention, as it features an $O$-linked carbadisaccharide structure between pericosine A-like and pericosine B-like moieties with opposite absolute configurations and exists as a mixture of enantiomers [1]. In the course of our continuing studies on the total synthesis of marine natural products, we realized the first total syntheses of both enantiomers of 4 and its six stereoisomers, further elucidating their selective $\alpha$-glucosidase inhibitory activities. The naturally preferred enantiomer (-)-4 was less active (half maximal (50\%) Inhibitory Concentration $\left.\left(\mathrm{IC}_{50}\right)=1.5 \times 10^{-3} \mathrm{M}\right)$ than the minor enantiomer $(+)-4\left(\mathrm{IC}_{50}=3.1 \times 10^{-5} \mathrm{M}\right)$, while synthetic analogue (-)-5 exhibited the highest $\alpha$-glucosidase inhibitory activity $\left(\mathrm{IC}_{50}=1.2 \times 10^{-5} \mathrm{M}, \sim 50\right.$ times lower than 
that of a positive control, deoxynojirimycin). Thus, pericosine E (4) is a promising seed for a new class of anti-diabetes drugs [10,11].<smiles>[X]C1C(C(=O)O[Na])=C[C@@H](O)[C@H](O)[C@@H]1O</smiles>

$(+)$-pericosine $A(1): X=C l$ $(+)$-pericosine $C(3): X=O M e$

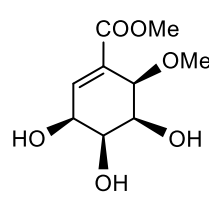

(+)-pericosine B (2)

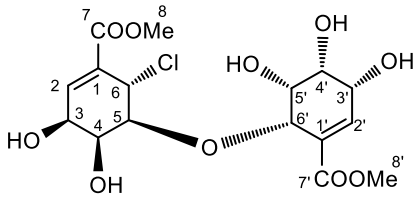

(+)-pericosine $\mathrm{E}(4)\left(\mathrm{IC}_{50} 3.1 \times 10^{-5} \mathrm{M}\right)$

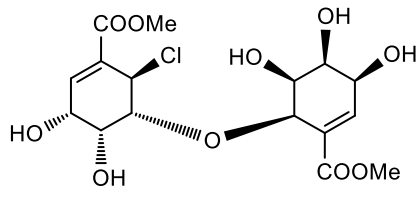

(-)-pericosine $\mathrm{E}(4)\left(\mathrm{IC}_{50} 1.5 \times 10^{-3} \mathrm{M}\right)$ naturally prefered enantiomer<smiles>COC(=O)C1=C[C@@H](O)[C@@H](O)[C@H](O)[C@H]1O[C@H]1[C@@H](O)[C@H](O)C=C(C(C)=O)[C@H]1Cl</smiles>

$(-)-5: I C_{50} 1.2 \times 10^{-5} \mathrm{M}$

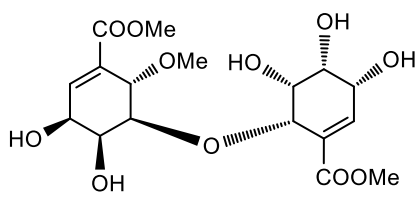

(+)-6 ( (+)-pericosine C-(-)-pericosine B)

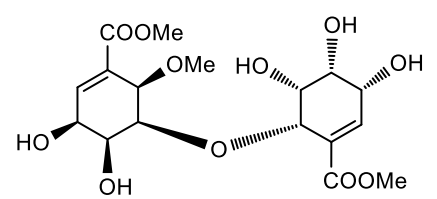

(-)-7 ( (+)-pericosine B-(-)-pericosine B)<smiles>COC(=O)C1=C[C@@H](O)[C@H](O)[C@H](OC[C@H]2C(C(=O)OC)=C[C@@H](O)[C@H](O)[C@@H]2O)[C@@H]1O</smiles>

(-)-8 ( (-)-pericosine C-(-)-pericosine B)<smiles>COC(=O)C1=C[C@@H](O)[C@@H](O)[C@H](O)[C@H]1O[C@H]1C(C(=O)OC)=C[C@@H](O)[C@H]1O</smiles>

9 ( (-)-pericosine B-(-)-pericosine B)

Figure 1. Natural pericosines (1-4) with synthetic 5 and newly designed analogs (6-9).

Considering the above, we herein aimed to design and synthesize pericosine $\mathrm{E}$ analogs bearing a methoxy group at C6 instead of a chlorine atom and elucidate the corresponding structure-activity relationships. The design of these targets was inspired by the possible existence of the hitherto unknown naturally occurring pericosine E-type $O$-linked carbadisaccharides comprising known pericosine B or $\mathrm{C}$ units with various combinations of chiralities, as the parent pericosine $\mathrm{E}$ is thought to be biologically synthesized from pericosines A and B. Moreover, we aimed to determine whether the replacement of the chlorine atom at C6 with a methoxy group influences enzyme inhibitory activity by electronic effect or size of the substituent. In our previous work, the characteristic structural pattern of pericosine E analogs was denoted as (donor, acceptor)-type for a better understanding of the puzzling stereochemistry with eight chiral centers in each compound. For example, (-)-4 was denoted as $(-\mathrm{pA},+\mathrm{pB})$-type, as it can be constructed from (-)-pericosine A and (+)-pericosine B moieties. A similar notation was used in the present paper. Inspection of naturally occurring possibilities resulted in the design and synthesis of novel carbadisaccharides 6, 7, 8, and 9, with $(+p C,-p B)-,(+p B,-p B)-,(-p C,-p B)-$, and $(-p B$, $-\mathrm{pB})$-type structures, respectively. The corresponding enantiomers were also synthesized.

Herein, we report the syntheses of sixteen pericosine E analogs bearing a methoxy group at C6 instead of a chlorine atom and evaluate their glycosidase inhibitory activities. In addition, results of the docking simulation on active compounds and $\alpha$-glucosidase is described.

\section{Results and Discussion}

\subsection{Syntheses of Pericosine E Analogs Methoxy-Substituted at C6}

All possible isomers derived from pericosine B or pericosine $C$ were considered. As mentioned in our previous paper, the acceptor of the coupling reaction was limited to trans-epoxide $\mathbf{1 1}$ enantiomers $[10,11]$. (+)-6, (-)-7, (-)-8, and (-)-9 were prepared following a previously reported strategy (Scheme 1). Both enantiomers of $\mathbf{1 0}$ and 15, which are synthetic precursors of pericosines $C$ and $B$ respectively, could be used as donor molecules in the Lewis-acid-catalyzed coupling reaction [12,13]. 


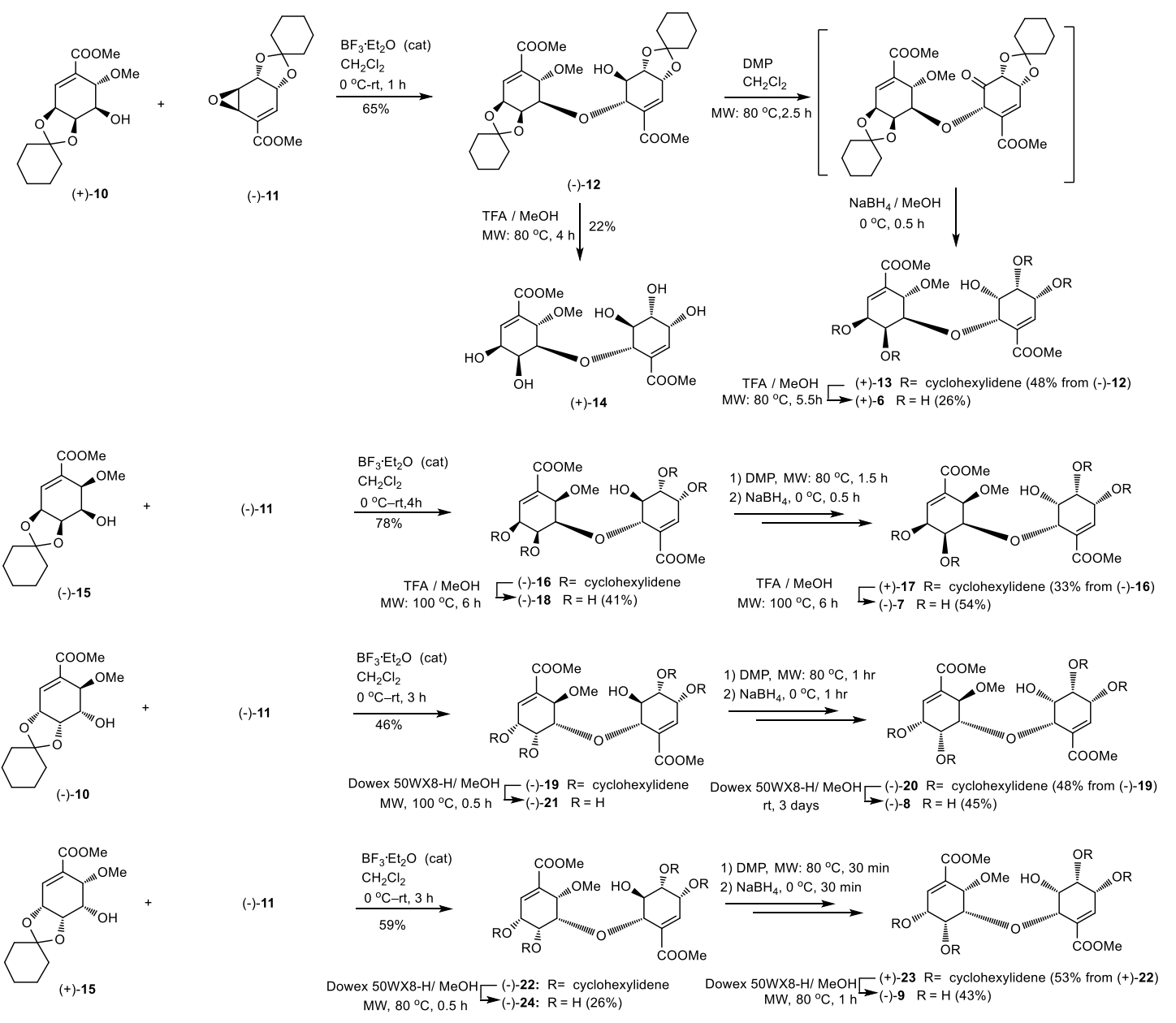

Scheme 1. Syntheses of pericosine E analogs methoxy-substituted at C6 from (-)-11.

The synthesis of (+)-6, which can be derived from (+)-pericosine C (3) and (-)-pericosine B (2), is discussed below as an example. $\mathrm{BF}_{3}$-catalyzed coupling between $(+)-10$ (the precursor of $\left.(+)-3\right)$ and (-)-11 (the synthetic intermediate of (-)-2) yielded (-)-12 (65\%). This compound (i.e., (-)-12) was treated with Dess-Martin periodinane (DMP) to afford a crude ketone that was used in the following reaction without purification by silica gel column chromatography to avoid double bond migration. The crude residue was treated with $\mathrm{NaBH}_{4}$ in $\mathrm{MeOH}$ to afford (+)-13 (48\% yield over two steps from (-)-12), which was converted to (+)-6 in 26\% yield by microwave (MW)-assisted acidic deprotection. Alternatively, the epimer (+)-14 was prepared by similar deprotection of (-)-12. Other targets, namely, $(-)-7-9$ and their epimers (-)-18, (-)-21, and (-)-24, were also prepared according to Scheme 1 under variable conditions. The corresponding enantiomers were synthesized by similar methods to afford sixteen C6-methoxylated pericosine E analogs. Both enantiomers of 10, 15, and $\mathbf{1 1}$ were prepared as described elsewhere [10-12]. The modified selective epoxidation of a cyclohexadiene precursor [10,11] with 1,1,1-trifluorodimethyloxirane to afford anti-epoxide $\mathbf{1 1}$ is described in the synthesis of the new compound (-)-15 (see Supplementary Materials: SM-3).

\subsection{Evaluation of Glycosidase Inhibitory Activities}

The synthesized compounds were subjected to glycosidase inhibitory activity assays (Table 1). Herein, $\alpha$-galactosidase (from green coffee bean) and $\beta$-galactosidase (from bovine lever) were used in addition to the three previously employed glycosidases ( $\alpha$-glucosidase, $\beta$-glucosidase, and $\alpha$-mannosidase) [11]. To facilitate comparison across studies, we used the same batches of the three abovementioned glycosidases as those employed before. Some compounds were not tested 
against all five enzymes because of the limited amount of materials. The first three rows of Table 1 relate to (-)- and (+)-pericosine E 4 and the most potent compound (-)-5 identified in a previous work.

Table 1. Glycosidase inhibitory activities of the synthesized compounds.

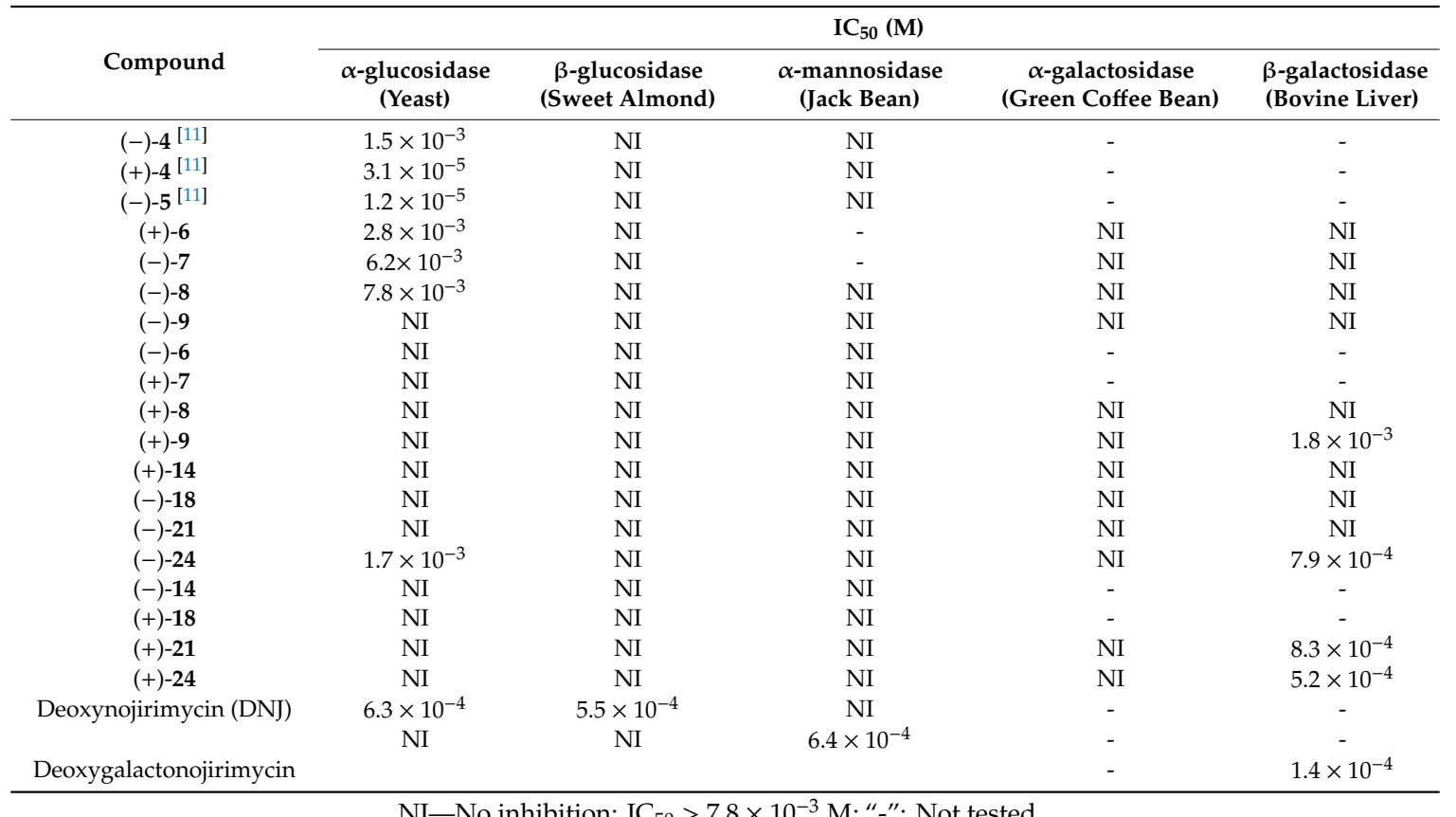

No compounds showed inhibitory activities against $\beta$-glucosidase, $\alpha$-mannosidase, and $\alpha$-galactosidase, while $\alpha$-glucosidase was moderately inhibited by (+)-6, (-)-7, (-)-8, and (-)-24. The most potent compound, $(-)-24\left(\mathrm{IC}_{50}=1.7 \times 10^{-3} \mathrm{M}\right)$, showed an activity close to that of (-)-pericosine $\mathrm{E}(4)\left(\mathrm{IC}_{50}=1.5 \times 10^{-3} \mathrm{M}\right)$. However, the replacement of a chlorine atom at $\mathrm{C} 6$ with a methoxy group decreased activity in general. For example, the $\alpha$-glucosidase inhibitory activity of $(-)-7\left(\mathrm{IC}_{50}=6.2 \times 10^{-3} \mathrm{M}\right)$ was four-fold lower than that of $(-)-4$, which had the same relative and absolute configuration. Moreover, the anti- $\alpha$-glucosidase activity of $(-)-8$ was approximately $1 / 600$ that of (-)-5. Similarly, compound (+)-8 was not active whereas the corresponding (+)-4 exhibited potent activity. Here, it should be mentioned that these conclusions regarding enzyme activity drawn from the $\mathrm{IC}_{50}$ values in this section are approximate.

The above results imply that original pericosine E analogs containing a chlorine atom at C6 are more potent $\alpha$-glucosidase inhibitors than their methoxy analogues. Notably, compounds featuring (-)-11 as an acceptor exhibited a certain anti- $\alpha$-glucosidase activity, except for (-)-18. These findings provided useful information for the design of new molecules with better activities.

Gratifyingly, some synthesized compounds, namely, (+)-9, (-)-24, (+)-21, and (+)-24, showed $\beta$-galactosidase inhibitory activities, featuring $(+)-\mathbf{1 1}$ as an acceptor, except for $(-)-\mathbf{2 4}$. The opposite preference for high $\alpha$-glucosidase and $\beta$-galactosidase inhibitory activities is interesting and might be valuable for future studies, as the design of new types of $\beta$-galactosidase inhibitors is an important and challenging task [14-17].

\subsection{Docking Simulation}

A molecular docking study using the Dock function [18] of Molecular Operating Environment (MOE) version 2018.0101 (Chemical Computing Group Inc., Quebec, Canada) was conducted for better understanding of the inhibitory mechanisms (Figures 2 and 3). The interactions between $\alpha$-glucosidase (Protein Data Bank (PDB) code 3A4A) [19] with compounds (-)-5 and (-)-24 as well as glucose were investigated using the MOE-Dock. 


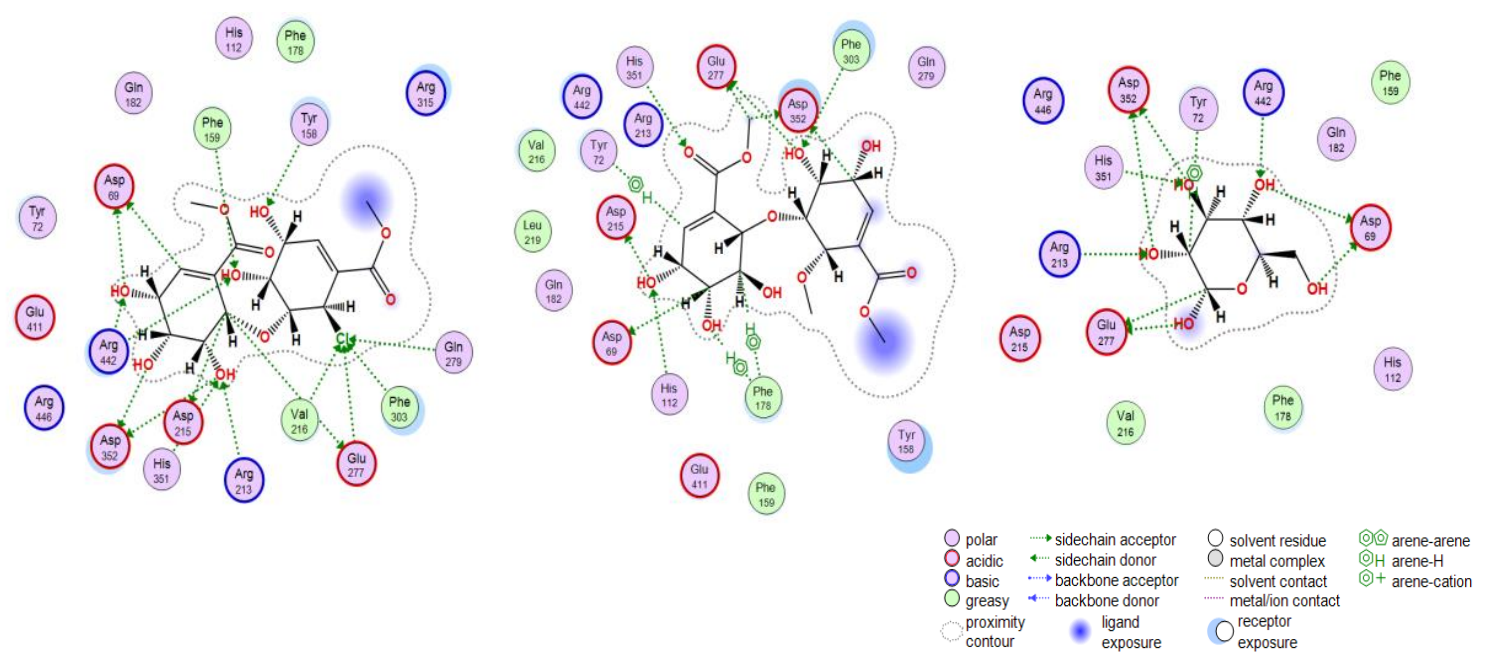

Figure 2. Docking results obtained from a set of pericosine E derivatives as $\alpha$-glucosidase inhibitors. Two-dimension interaction diagrams of compounds (-)-5 (left), (-)-24 (center), and glucose (right) with the $\alpha$-glucosidase binding cavity were depicted.

(A)

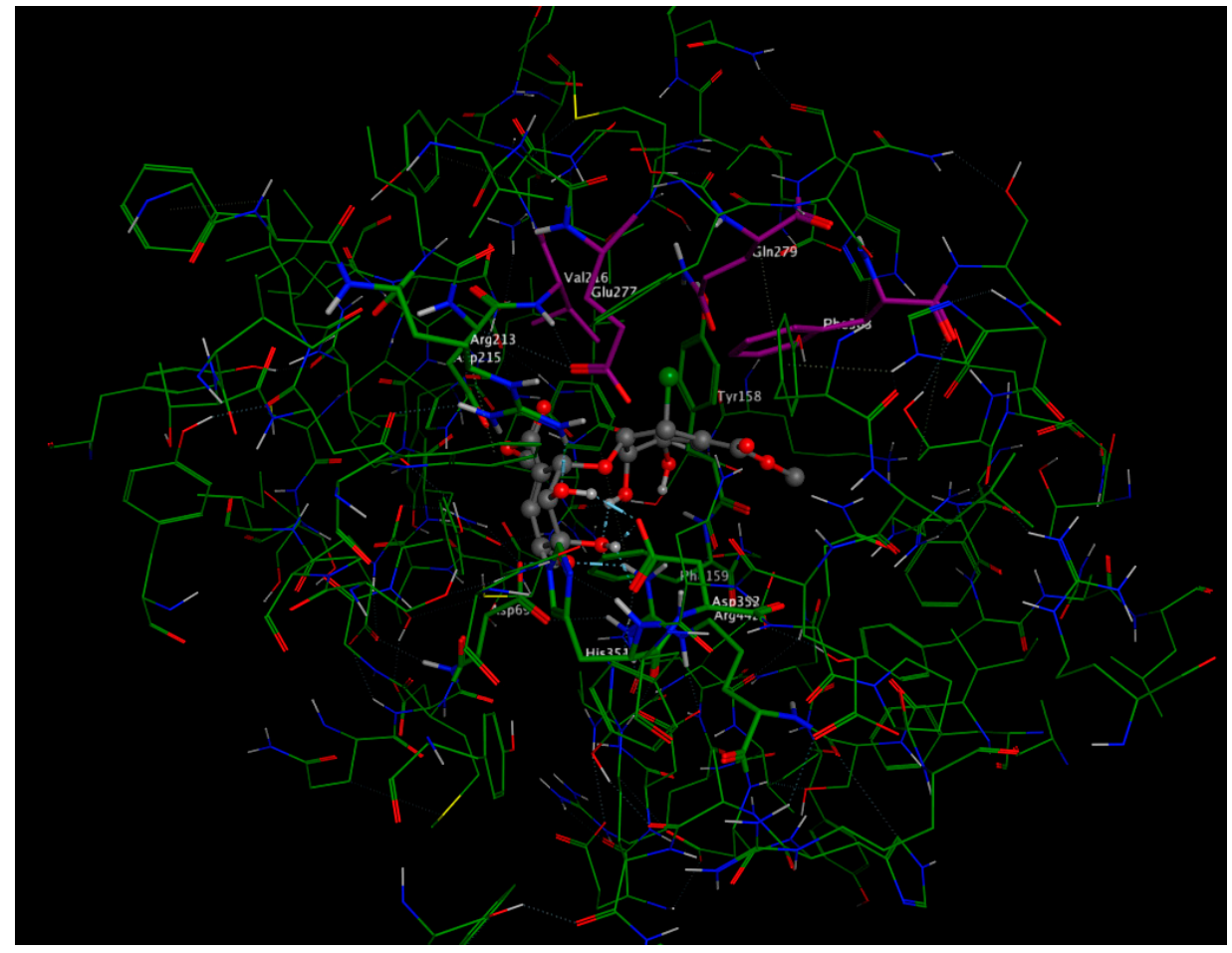

Figure 3. Cont. 
(B)

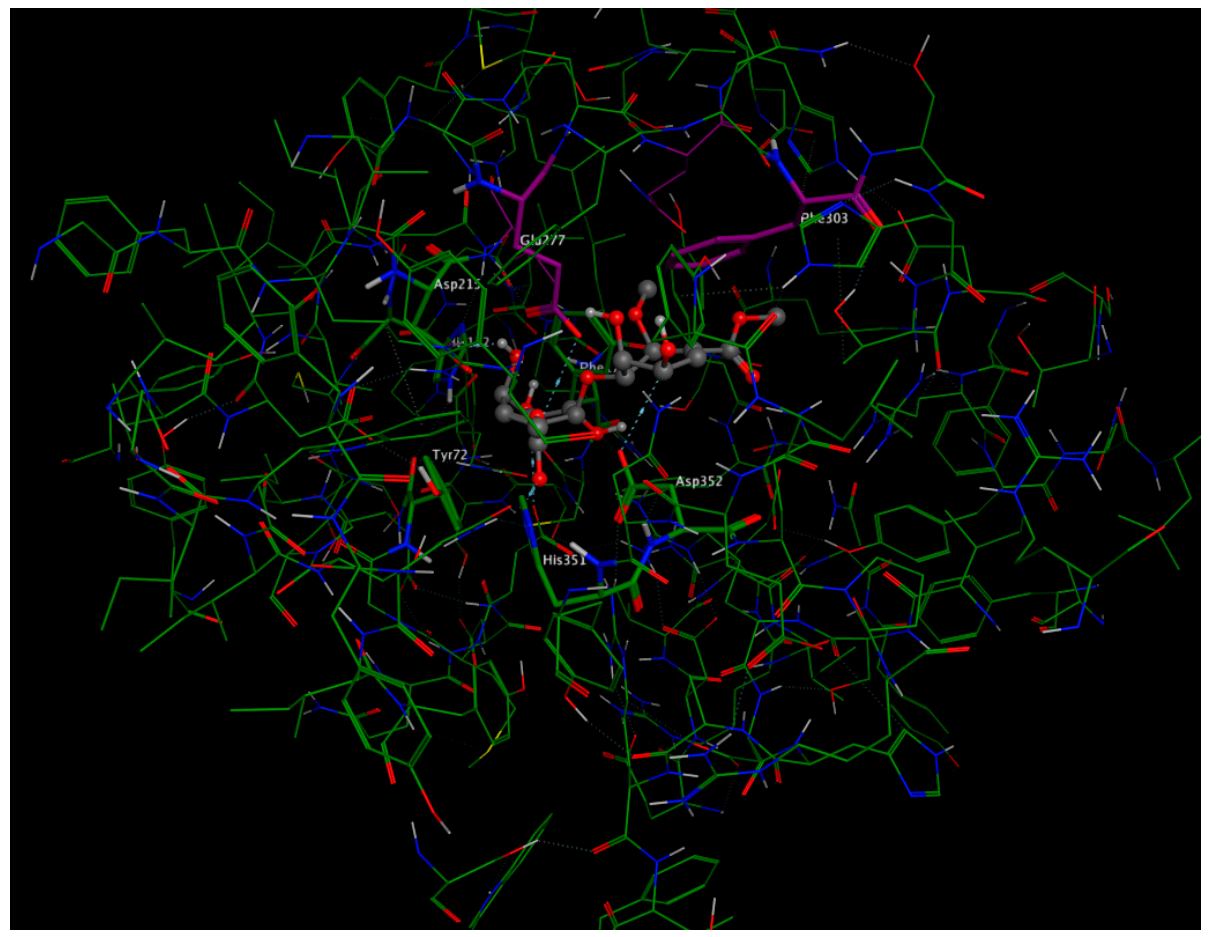

(C)

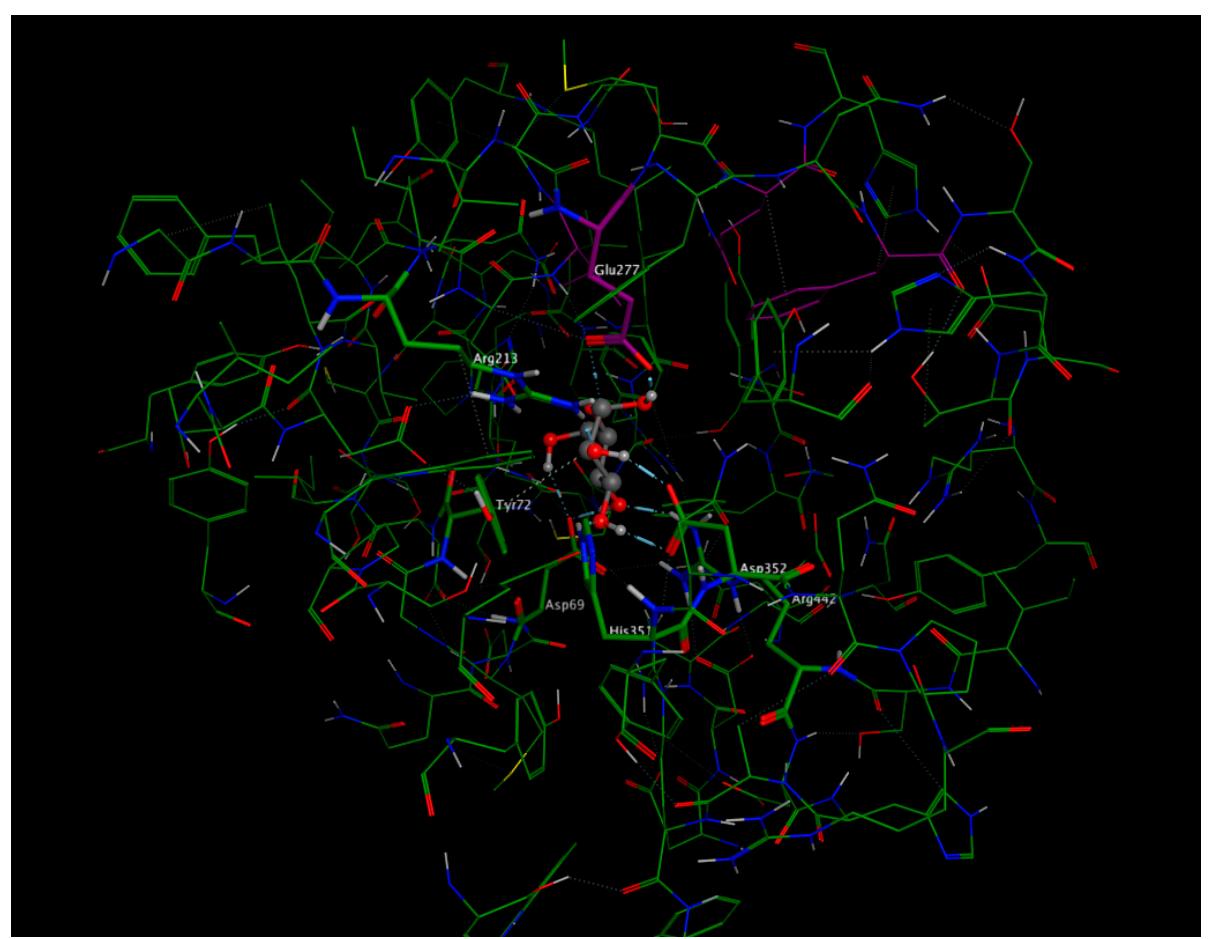

Figure 3. Protein-ligand interaction graphs of the active pocket of $\alpha$-glucosidase with compounds, (A): (-)-5, (B) (-)-24, (C) glucose. The chlorine atom in the compound (-)-5 is shown in green, and the amino acid residues such as Val216, Glu277, Gln279, and Phe303 that interact with the chlorine atom are shown in purple.

As a result, the peripheral amino acids important for glucose binding were observed to be involved in the binding of compounds (-)-5 and (-)-24. It was shown that the chlorine atom of compound (-)-5 
could form hydrogen bonds with the surrounding amino acid residues such as Val216, Glu277, Gln279, and Phe303. No such binding was observed for glucose and the methoxy group of the compound (-)-24. Furthermore, the configurations of compound (-)-5 and compound (-)-24 were quite different, and the surrounding amino acids that bind $\alpha$-glucosidase were also different.

Tang and co-workers identified 12 amino acid residues, including Val 216, Glu 277, Gln 279, and Phe 303, that interact with the $\alpha$-glucosidase inhibitors salvianolic acid A and salvianolic acid C. The chlorine-containing compound (-)-5 might inhibit $\alpha$-glucosidase in a similar binding manner to those inhibitors [20].

Comparisons of affinity scores between different substrates are known to be useful in assessing agonist/antagonist activity [21]. The binding affinity scores of compounds (-)-5, (-)-24, and glucose were $-6.8,-4.7$, and $-8.2 \mathrm{kcal} / \mathrm{mol}$, respectively. Glucose, which is included as a partial residue of natural substrates, exhibited the highest affinity among the three docked compounds. Also, the affinities of compounds (-)-5 and (-)-24 reflected the inhibitory activities, $1.2 \times 10^{-5}$ and $1.7 \times 10^{-3}$, respectively. These results indicate that the docking studies were achieved with a certain accuracy. On the other hand, the threshold value of the hydrogen bond strength depicted in Figure 2 was set to $-1.0 \mathrm{kcal} / \mathrm{mol}$ for glucose and $-0.1 \mathrm{kcal} / \mathrm{mol}$ for derivatives. Compound ( - ) -5 is considered to contribute to stronger binding affinity by interacting with more peripheral amino acids than compound (-)-24. However, the accuracy of the docking simulation is limited. It is considered necessary to perform molecular dynamics (MD) simulation to obtain more detailed knowledge.

$\alpha$-glucosidase $3 \mathrm{~A} 4 \mathrm{~A}$ is one of the crystal structures representative of $\alpha$-glucosidase and is generally used for the study of this enzyme [22-25]. On the other hand, $\alpha$-glucosidase, $\beta$-glucosidase, $\alpha$-mannosidase, $\alpha$-galactosidase, and $\beta$-galactosidase used in this study showed different inhibition profiles against various pericosine derivatives. These results suggest that the steric configurations of amino acids at the ligand-binding site among these enzymes are significantly different. The relationship among the amino acid sequences of the ligand-binding sites and the inhibitory activities will be rigorously evaluated in a subsequent study.

\section{Conclusions}

We designed and synthesized 16 pericosine $\mathrm{E}$ analogs bearing a methoxy group at C6 and tested their inhibitory activities against five glycosidases. Among the 16 compounds, four exhibited lower $\alpha$-glucosidase inhibitory activities than the corresponding chlorine-containing species. Thus, the chlorine atom at C6 in pericosine E analogs was concluded to play an important role in determining $\alpha$-glucosidase inhibitory activity. The identified active compounds generally featured the (-)-pB moiety as an acceptor. Contrarily, some compounds mainly comprising the (+)-pB moiety showed $\beta$-galactosidase inhibitory activity, with (-)-24 acting as a dual inhibitor. Docking simulation suggested that (-)-24 synthesized in this study binds $\alpha$-glucosidase in different manner to more potent $(-)-5$, whose chlorine atom forms hydrogen bonds with the surrounding amino acid residues.

\section{Experimental}

\subsection{General}

Infrared (IR) spectra were recorded on a 1720X Fourier transformation-infrared (FT-IR) spectrometer (Perkin Elmer, MA, USA) or an IRAffinity-1S FT-IR spectrometer (Shimadzu, Kyoto, Japan). High-resolution mass spectra (HRMS) were recorded on a JMS-700 (2) mass spectrometer (JEOL, Tokyo, Japan). Nuclear magnetic resonance (NMR) spectra were recorded at $27^{\circ} \mathrm{C}$ on $400-\mathrm{MR}-\mathrm{DD} 2$ (Agilent Technologies, CA, USA) and 600-DD2 (Agilent Technologies, CA, USA) instruments in $\mathrm{CDCl}_{3}$ or acetone- $d_{6}$ using tetramethylsilane as an internal standard. Specific rotations were measured with a JASCO P-2300 spectrometer (JASCO Co., Tokyo, Japan). Liquid column chromatography was conducted on silica gel (Fuji Silysia FL-60D). Analytical thin layer chromatography (TLC) was performed on Silicagel $70 \mathrm{~F}_{254}$ plates (Wako Pure Chemical Industries, Tokyo, Japan), and compounds 
were detected by dipping the plates into an ethanolic solution of phosphomolybdic acid followed by heating. Microwave (MW)-aided reactions were carried out in a Biotage Initiator ${ }^{\circledR}$ reactor (PartnerTech Atvidaberg AB for Biotage Sweden AB, Uppsala, Sweden). $\mathrm{NaBH}_{4}$ and trifluoroacetic acid (TFA) were purchased from Wako Pure Chemical Industries (Wako Pure Chemical Industries, Tokyo, Japan). $\mathrm{BF}_{3} \cdot \mathrm{Et}_{2} \mathrm{O}$ was purchased from Sigma-Aldrich Co., LLC (St. Lewis, MO, USA). DMP was purchased from TCI (Tokyo Chemical Industry Co., Ltd., Tokyo, Japan). (-)-Shikimic acid and (-)-quinic acid were purchased from Carbosynth, Ltd. (UK) and Merck (Merck \& Co., Inc., Darmstadt, Germany), respectively. $\alpha$-Glucosidase (yeast, lot 26010), $\beta$-glucosidase (sweet almond, lot 81241 ), $\alpha$-mannosidase (Jack Bean, lot 055K7047), $\alpha$-galactosidase (green coffee bean, lot SMBP1296V), $\beta$-galactosidase (bovine liver, lot SMBL0488V), and deoxymannojirimycin were purchased from Sigma-Aldrich Co., LLC (St. Lewis, MO, USA). Deoxygalactonojirimycin was purchased from Funakoshi Co., Ltd., Tokyo, Japan). 1-Deoxynojirimycin (DNJ) was isolated from the leaves of Morus alba L. (Procedure for isolation of $\mathrm{DNJ}$ is described in Section 4.5.)

\subsection{Condensation of 10 or 15 with 11}

General procedure (synthesis of (-)-12, Scheme 1): To a solution of (+)-10 (68.4 mg, $0.23 \mathrm{mmol})$ and anti-epoxide (-)-11 (50.9 mg, $0.15 \mathrm{mmol})$ in $\mathrm{CH}_{2} \mathrm{Cl}_{2}(0.15 \mathrm{~mL})$ was added $\mathrm{BF}_{3} \cdot \mathrm{Et}_{2} \mathrm{O}(3 \mu \mathrm{L}$, $0.025 \mathrm{mmol})$ at $0{ }^{\circ} \mathrm{C}$. After $1 \mathrm{~h}$ of stirring, the reaction mixture was treated with $\mathrm{Et}_{3} \mathrm{~N}(20 \mu \mathrm{L}, 0.14 \mathrm{mmol})$ and concentrated under vacuum to afford a crude residue that was purified by silica gel column chromatography (eluent $=$ hexane:EtOAc, 1:1 v/v) to afford $(-)-12(68.8 \mathrm{mg}, 65 \%)$ as a colorless oil.

(-)-12: oil; $[\alpha]_{\mathrm{D}}^{20}-7.2$ (c 1.175, $\left.\mathrm{CHCl}_{3}\right)$; IR (film) $v_{\max } 3438(\mathrm{OH}), 1726(\mathrm{C}=\mathrm{O}), 1658(\mathrm{C}=\mathrm{C}) \mathrm{cm}^{-1}$; ${ }^{1} \mathrm{H}-\mathrm{NMR}$ (acetone- $\left.d_{6}, 400 \mathrm{MHz}, \mathrm{ppm}\right) \delta 1.30-1.70(20 \mathrm{H}, \mathrm{m}), 3.41$ (3H, s, $\left.6^{\prime}-\mathrm{OMe}\right), 3.73$ (3H, s, COOMe), $3.75(3 \mathrm{H}, \mathrm{s}, \mathrm{COOMe}), 4.01-4.04\left(1 \mathrm{H}, \mathrm{m}, \mathrm{H}-5^{\prime}\right), 4.21(1 \mathrm{H}$, overlapped, H-5), $4.23(1 \mathrm{H}$, overlapped, H-6), $4.25(1 \mathrm{H}$, overlapped, H-4' $), 4.37\left(1 \mathrm{H}, \mathrm{br} \mathrm{d}, J=5.4 \mathrm{~Hz}, \mathrm{H}-6^{\prime}\right), 4.58\left(1 \mathrm{H}, \mathrm{d}, J=3.3 \mathrm{~Hz}, 5^{\prime}-\mathrm{OH}\right)$, $4.70\left(1 \mathrm{H}, \mathrm{ddd}, J=6.1,3.9,0.9 \mathrm{~Hz}, \mathrm{H}-3^{\prime}\right), 4.74(1 \mathrm{H}, \mathrm{dd}, J=5.6,2.3 \mathrm{~Hz}, \mathrm{H}-4), 4.78(1 \mathrm{H}, \mathrm{ddd}, J=5.7,2.7$, $1.2 \mathrm{~Hz}, \mathrm{H}-3), 6.50(1 \mathrm{H}, \mathrm{dd}, J=2.5,1.0 \mathrm{~Hz}, \mathrm{H}-2), 6.55\left(1 \mathrm{H}, \mathrm{dd}, J=3.7,1.2 \mathrm{~Hz}, \mathrm{H}-2^{\prime}\right) ;{ }^{13} \mathrm{C}-\mathrm{NMR}$ (acetone- $d_{6}$, $100 \mathrm{MHz}, \mathrm{ppm}) \delta 24.47\left(\mathrm{CH}_{2}\right), 24.51\left(\mathrm{CH}_{2}\right), 24.69\left(\mathrm{CH}_{2}\right), 24.72\left(\mathrm{CH}_{2}\right), 25.7\left(\mathrm{CH}_{2}\right), 25.8\left(\mathrm{CH}_{2}\right), 35.8\left(\mathrm{CH}_{2}\right)$, $36.3\left(\mathrm{CH}_{2}\right), 37.6\left(\mathrm{CH}_{2}\right), 38.7\left(\mathrm{CH}_{2}\right), 52.0\left(\mathrm{CH}_{3}, \mathrm{C}-8\right), 52.1\left(\mathrm{CH}_{3}, \mathrm{C}-8^{\prime}\right), 60.3\left(\mathrm{CH}_{3}, 6^{\prime}-\mathrm{OMe}\right), 71.6(\mathrm{CH}$, C-3'), $72.5(\mathrm{CH}, \mathrm{C}-3), 72.8\left(\mathrm{CH}, \mathrm{C}-5^{\prime}\right), 74.0(\mathrm{CH}, \mathrm{C}-4), 75.9(\mathrm{CH}, \mathrm{C}-6), 76.2\left(\mathrm{CH}, \mathrm{C}-4^{\prime}\right), 77.0\left(\mathrm{CH}, \mathrm{C}-6^{\prime}\right)$, 80.5 (C, C-5), $111.1(\mathrm{Cq}), 111.3(\mathrm{Cq}), 133.38$ (Cq, C-1), $133.42(\mathrm{CH}, \mathrm{C}-2), 134.8\left(\mathrm{Cq}, \mathrm{C}-1^{\prime}\right), 136.1$ (CH, C-2'), 167.39 (Cq, C-7), 167.43 (Cq, C-7'); high-resolution electron impact mass spectrum (HREIMS) $\mathrm{m} / \mathrm{z}$ calcd for $\mathrm{C}_{29} \mathrm{H}_{40} \mathrm{O}_{11}(\mathrm{M})^{+} 564.2571$, found 564.2570 .

(+)-12 (51.2 $\mathrm{mg}, 90 \%)$ was prepared from $(-)-\mathbf{1 0}(30 \mathrm{mg}, 0.10 \mathrm{mmol})$ and $(+)-\mathbf{1 1}(40.0 \mathrm{mg}, 0.15 \mathrm{mmol})$ : oil; $[\alpha]_{\mathrm{D}}^{20}+7.7\left(\right.$ c 0.43, $\left.\mathrm{CHCl}_{3}\right)$; IR (film) $v_{\max } 3431(\mathrm{OH}), 1727(\mathrm{C}=\mathrm{O}), 1658(\mathrm{C}=\mathrm{C}) \mathrm{cm}^{-1} ;{ }^{1} \mathrm{H}-\mathrm{NMR}$ (acetone- $\left.d_{6}, 600 \mathrm{MHz}, \mathrm{ppm}\right) \delta 1.50-1.70(20 \mathrm{H}, \mathrm{m}), 3.41\left(3 \mathrm{H}, \mathrm{s}, 6^{\prime}-\mathrm{OMe}\right), 3.73(3 \mathrm{H}, \mathrm{s}, \mathrm{COOMe}), 3.75(3 \mathrm{H}, \mathrm{s}$, COOMe), $4.07\left(1 \mathrm{H}, \mathrm{ddd}, J=6.8,5.6,3.5 \mathrm{~Hz}, \mathrm{H}-5^{\prime}\right), 4.21(1 \mathrm{H}, \mathrm{dd}, J=6.8,2.9 \mathrm{~Hz}, \mathrm{H}-5), 4.23(1 \mathrm{H}, \mathrm{dt}, J=6.8$, $1.2 \mathrm{~Hz}, \mathrm{H}-6), 4.25\left(1 \mathrm{H}, \mathrm{t}, J=6.5 \mathrm{~Hz}, \mathrm{H}-4^{\prime}\right), 4.37\left(1 \mathrm{H}, \mathrm{ddd}, J=5.6,1.2,1.1 \mathrm{~Hz}, \mathrm{H}-6^{\prime}\right), 4.60(1 \mathrm{H}, \mathrm{d}, J=3.5 \mathrm{~Hz}$, $\mathrm{OH}), 4.70\left(1 \mathrm{H}, \mathrm{ddd}, J=6.1,3.8,1.1 \mathrm{~Hz}, \mathrm{H}-3^{\prime}\right), 4.74(1 \mathrm{H}, \mathrm{ddd}, J=5.9,2.9,0.8 \mathrm{~Hz}, \mathrm{H}-4), 4.78(1 \mathrm{H}, \mathrm{ddd}$, $J=5.9,3.0,1.5 \mathrm{~Hz}, \mathrm{H}-3), 6.50(1 \mathrm{H}, \mathrm{ddd}, J=3.0,1.2,0.9 \mathrm{~Hz}, \mathrm{H}-2), 6.55\left(1 \mathrm{H}, \mathrm{dd}, J=3.8,1.2 \mathrm{~Hz}, \mathrm{H}-2^{\prime}\right)$; ${ }^{13} \mathrm{C}-\mathrm{NMR}$ (acetone- $\left.d_{6}, 150 \mathrm{MHz}, \mathrm{ppm}\right) \delta 24.47\left(\mathrm{CH}_{2}\right), 24.51\left(\mathrm{CH}_{2}\right), 24.68\left(\mathrm{CH}_{2}\right), 24.70\left(\mathrm{CH}_{2}\right), 25.7\left(\mathrm{CH}_{2}\right)$, $25.8\left(\mathrm{CH}_{2}\right), 35.7\left(\mathrm{CH}_{2}\right), 36.3\left(\mathrm{CH}_{2}\right), 37.6\left(\mathrm{CH}_{2}\right), 38.7\left(\mathrm{CH}_{2}\right), 52.0\left(\mathrm{CH}_{3}, \mathrm{C}-8\right.$ or C-8'), $52.1\left(\mathrm{CH}_{3}, \mathrm{C}-8\right.$ or $\left.\mathrm{C}-8^{\prime}\right), 60.3\left(\mathrm{CH}_{3}, 6^{\prime}-\mathrm{OMe}\right), 71.6\left(\mathrm{CH}, \mathrm{C}-3^{\prime}\right), 72.5(\mathrm{CH}, \mathrm{C}-3), 72.7\left(\mathrm{CH}, \mathrm{C}-5^{\prime}\right), 74.0(\mathrm{CH}, \mathrm{C}-4), 75.9(\mathrm{CH}, \mathrm{C}-6)$, $76.2\left(\mathrm{CH}, \mathrm{C}-4^{\prime}\right), 77.0\left(\mathrm{CH}, \mathrm{C}-6^{\prime}\right), 80.5(\mathrm{C}, \mathrm{C}-5), 111.1(\mathrm{Cq}), 111.3(\mathrm{Cq}), 133.4(\mathrm{Cq}, \mathrm{C}-1), 133.5(\mathrm{CH}, \mathrm{C}-2)$, 134.7 (Cq, C-1'), 136.1 (CH, C-2'), 167.40 (Cq, C-7), 167.44 (Cq, C-7'); HRMS m/z calcd for $\mathrm{C}_{29} \mathrm{H}_{40} \mathrm{O}_{11}$ $(\mathrm{M})^{+} 564.2571$, found 564.2574 .

(-)-16 (150.3 mg, $78 \%$ ) was prepared from (+)-15 (101.4 mg, $0.34 \mathrm{mmol})$ and (-)-11 (94.6 mg, $0.36 \mathrm{mmol})$ : oil; $[\alpha]_{\mathrm{D}}^{20}-75.6\left(c 0.60, \mathrm{CHCl}_{3}\right)$; IR (film) $v_{\max } 3477(\mathrm{OH}), 1722(\mathrm{C}=\mathrm{O}), 1657(\mathrm{C}=\mathrm{C}) \mathrm{cm}^{-1}$; ${ }^{1} \mathrm{H}-\mathrm{NMR}\left(\mathrm{C}_{6} \mathrm{D}_{6}, 300 \mathrm{MHz}, \mathrm{ppm}\right) \delta 1.00-1.90(20 \mathrm{H}, \mathrm{m}), 3.33(3 \mathrm{H}, \mathrm{s}, \mathrm{H}-8), 3.35$ (3H, s, H-8'), $3.67(3 \mathrm{H}, \mathrm{s}$, OMe), $4.02\left(1 \mathrm{H}, \mathrm{d}, J=4.4 \mathrm{~Hz}, \mathrm{H}-6^{\prime}\right), 4.04\left(1 \mathrm{H}, \mathrm{dd}, J=21.1,8.2 \mathrm{~Hz}, \mathrm{H}-5^{\prime}\right), 4.16(1 \mathrm{H}, \mathrm{dd}, J=4.4,1.2 \mathrm{~Hz}$, H-5), 4.21 (1H, overlapped, H-4'), $4.27(1 \mathrm{H}, \mathrm{dd}, J=6.5,3.6 \mathrm{~Hz}, \mathrm{H}-3), 4.35(1 \mathrm{H}, \mathrm{ddd}, J=6.4,3.9,0.5 \mathrm{~Hz}$, 
H-3'), $4.50\left(1 \mathrm{H}, \mathrm{s}, 5^{\prime}-\mathrm{OH}\right), 4.64(1 \mathrm{H}, \mathrm{dd}, J=4.4,1.2 \mathrm{~Hz}, \mathrm{H}-6), 4.66(1 \mathrm{H}, \mathrm{dd}, J=3.6,1.5 \mathrm{~Hz}, \mathrm{H}-4), 6.57(1 \mathrm{H}$, $\left.\mathrm{dd}, J=3.8,1.5 \mathrm{~Hz}, \mathrm{H}-2^{\prime}\right), 6.79(1 \mathrm{H}, \mathrm{d}, J=2.9 \mathrm{~Hz}, \mathrm{H}-2) ;{ }^{13} \mathrm{C}-\mathrm{NMR}$ (acetone- $\left.d_{6}, 75 \mathrm{MHz}, \mathrm{ppm}\right) \delta 24.7$ $\left(\mathrm{CH}_{2}\right), 24.8\left(2 \times \mathrm{CH}_{2}\right), 25.0\left(\mathrm{CH}_{2}\right), 25.7\left(\mathrm{CH}_{2}\right), 26.0\left(\mathrm{CH}_{2}\right), 36.4\left(\mathrm{CH}_{2}\right), 36.6\left(\mathrm{CH}_{2}\right), 38.4\left(\mathrm{CH}_{2}\right), 38.9\left(\mathrm{CH}_{2}\right)$, $52.1\left(2 \times \mathrm{CH}_{3}, \mathrm{C}-8,8^{\prime}\right), 62.3\left(\mathrm{CH}_{3}, 6^{\prime}-\mathrm{OMe}\right), 72.0\left(\mathrm{CH}, \mathrm{C}-3^{\prime}\right), 72.1(\mathrm{CH}, \mathrm{C}-4), 73.3(\mathrm{CH}, \mathrm{C}-3), 73.6(\mathrm{CH}$, C-6), $74.9\left(\mathrm{CH}, \mathrm{C}-5^{\prime}\right), 77.1\left(\mathrm{CH}, \mathrm{C}-4^{\prime}\right), 78.1\left(\mathrm{CH}, \mathrm{C}-6^{\prime}\right), 79.4(\mathrm{CH}, \mathrm{C}-5), 112.0(\mathrm{Cq}), 112.9(\mathrm{Cq}), 131.6(\mathrm{Cq}$, C-1), 132.9 (CH, C-2'), 136.9 (Cq, C-1'), 136.9 (CH, C-2) 166.8 (Cq, C-7), 166.9 (Cq, C-7'); HREIMS m/z calcd for $\mathrm{C}_{29} \mathrm{H}_{40} \mathrm{O}_{11}(\mathrm{M})^{+}$564.2571, found 564.2567.

(+)-16 (76.2 mg, 90\%) was prepared from (-)-15 (45.0 mg, $0.15 \mathrm{mmol})$ and (+)-11 (40.0 mg, $0.15 \mathrm{mmol})$ : oil; $[\alpha]_{\mathrm{D}}^{20}+75.4\left(c 0.82, \mathrm{CHCl}_{3}\right)$; IR (film) $v_{\max } 3488(\mathrm{OH}), 1723(\mathrm{C}=\mathrm{O}), 1653(\mathrm{C}=\mathrm{C}) \mathrm{cm}^{-1}$; ${ }^{1} \mathrm{H}-\mathrm{NMR}\left(\mathrm{C}_{6} \mathrm{D}_{6}, 600 \mathrm{MHz}, \mathrm{ppm}\right) \delta 1.50-1.90(20 \mathrm{H}, \mathrm{m}), 3.36(3 \mathrm{H}, \mathrm{s}, \mathrm{COOMe}), 3.39(3 \mathrm{H}, \mathrm{s}, \mathrm{COOMe})$, $3.66\left(3 \mathrm{H}, \mathrm{s}, 6^{\prime}-\mathrm{OMe}\right), 4.02-4.08\left(2 \mathrm{H}, \mathrm{m}, \mathrm{H}-5^{\prime}\right.$ and $\left.\mathrm{H}-6^{\prime}\right), 4.15(1 \mathrm{H}, \mathrm{dd}, J=4.7,3.3 \mathrm{~Hz}, \mathrm{H}-5), 4.21(1 \mathrm{H}, \mathrm{ddd}$, $\left.J=6.8,6.7,2.1 \mathrm{~Hz}, \mathrm{H}-4^{\prime}\right), 4.31(1 \mathrm{H}, \mathrm{ddd}, J=5.8,3.2,0.6 \mathrm{~Hz}, \mathrm{H}-3), 4.39(1 \mathrm{H}, \mathrm{ddd}, J=6.4,3.8,0.8 \mathrm{~Hz}$, H-3'), $4.47\left(1 \mathrm{H}, \mathrm{s}, 5^{\prime}-\mathrm{OH}\right), 4.62(1 \mathrm{H}, \mathrm{d}, J=4.7 \mathrm{~Hz}, \mathrm{H}-6), 4.66(1 \mathrm{H}, \mathrm{dd}, J=5.9,2.7 \mathrm{~Hz}, \mathrm{H}-4), 6.59(1 \mathrm{H}$, $\left.\mathrm{dd}, J=3.6,1.4 \mathrm{~Hz}, \mathrm{H}-2^{\prime}\right), 6.79(1 \mathrm{H}, \mathrm{dd}, J=3.2,0.5 \mathrm{~Hz}, \mathrm{H}-2) ;{ }^{13} \mathrm{C}-\mathrm{NMR}\left(\mathrm{C}_{6} \mathrm{D}_{6}, 150 \mathrm{MHz}, \mathrm{ppm}\right) \delta 24.1$ $\left(2 \times \mathrm{CH}_{2}\right), 24.3\left(\mathrm{CH}_{2}\right), 24.4\left(\mathrm{CH}_{2}\right), 25.2\left(\mathrm{CH}_{2}\right), 25.4\left(\mathrm{CH}_{2}\right), 35.8\left(\mathrm{CH}_{2}\right), 36.1\left(\mathrm{CH}_{2}\right), 37.8\left(\mathrm{CH}_{2}\right), 38.3\left(\mathrm{CH}_{2}\right)$, $51.56\left(\mathrm{CH}_{3}, \mathrm{C}-8\right), 51.60\left(\mathrm{CH}_{3}, \mathrm{C}-8^{\prime}\right), 61.7\left(\mathrm{CH}_{3}, 6^{\prime}-\mathrm{OMe}\right), 71.4\left(\mathrm{CH}, \mathrm{C}-3^{\prime}\right), 71.5(\mathrm{CH}, \mathrm{C}-4), 72.8(\mathrm{CH}, \mathrm{C}-3)$, $73.1(\mathrm{CH}, \mathrm{C}-6), 74.2\left(\mathrm{CH}, \mathrm{C}-5^{\prime}\right), 76.5\left(\mathrm{CH}, \mathrm{C}-4^{\prime}\right), 77.5\left(\mathrm{CH}, \mathrm{C}-6^{\prime}\right), 78.9(\mathrm{CH}, \mathrm{C}-5), 111.4(\mathrm{Cq}), 112.4(\mathrm{Cq})$, 131.1 (Cq, C-1), 132.5 (CH, C-2'), 136.2 (Cq, C-1'), 136.4 (CH, C-2) 166.2 (Cq, C-7), 166.4.(Cq, C-7'); HREIMS $\mathrm{m} / z$ calcd for $\mathrm{C}_{29} \mathrm{H}_{40} \mathrm{O}_{11}(\mathrm{M})^{+} 564.2571$, found 564.2570 .

(-)-19 (139 mg, 46\%) was prepared from (-)-10 (187 mg, $0.70 \mathrm{mmol})$ and (-)-11 (113 mg, $0.54 \mathrm{mmol})$ : white powder; $\mathrm{mp} 165-170{ }^{\circ} \mathrm{C}:[\alpha]_{\mathrm{D}}^{20}-48.4\left(\right.$ c $\left.0.1, \mathrm{CHCl}_{3}\right)$; IR $(\mathrm{KBr}) v_{\max } 3422(\mathrm{OH})$, $1726(\mathrm{C}=\mathrm{O}), 1438(\mathrm{C}=\mathrm{C}) \mathrm{cm}^{-1} ;{ }^{1} \mathrm{H}-\mathrm{NMR}\left(\mathrm{CDCl}_{3}, 600 \mathrm{MHz}, \mathrm{ppm}\right) \delta 1.30-1.80(20 \mathrm{H}, \mathrm{m}), 3.71(3 \mathrm{H}, \mathrm{s}$, 6'-OMe), $3.795(3 \mathrm{H}, \mathrm{s}, \mathrm{COOMe}), 3.796(3 \mathrm{H}, \mathrm{s}, \mathrm{COOMe}), 3.91\left(1 \mathrm{H}, \mathrm{ddd}, J=9.4,7.3,2.6 \mathrm{~Hz}, \mathrm{H}-5^{\prime}\right)$, $4.05(1 \mathrm{H}, \mathrm{dd}, J=8.5,2.3 \mathrm{~Hz}, \mathrm{H}-5), 4.13\left(1 \mathrm{H}, \mathrm{dd}, J=9.1,6.5 \mathrm{~Hz}, \mathrm{H}-4^{\prime}\right), 4.25(1 \mathrm{H}, \mathrm{ddd}, J=7.7,1.8,1.4 \mathrm{~Hz}$, H-5'), $4.41(1 \mathrm{H}, \mathrm{ddd}, J=8.5,1.8,1.7 \mathrm{~Hz}, \mathrm{H}-6), 4.61\left(1 \mathrm{H}\right.$, overlapped, $\left.\mathrm{H}-3^{\prime}\right), 4.62(1 \mathrm{H}$, overlapped, $\mathrm{H}-3)$, $4.84(1 \mathrm{H}, \mathrm{ddd}, J=5.6,2.1,1.2 \mathrm{~Hz}, \mathrm{H}-4), 4.97(1 \mathrm{H}, \mathrm{d}, J=2.6 \mathrm{~Hz}, \mathrm{OH}), 6.42(1 \mathrm{H}, \mathrm{ddd}, J=2.9,1.8,1.3 \mathrm{~Hz}$, $\mathrm{H}-2), 6.60\left(1 \mathrm{H}, \mathrm{dd}, J=4.4,2.0 \mathrm{~Hz}, \mathrm{H}-2^{\prime}\right) ;{ }^{13} \mathrm{C}-\mathrm{NMR}\left(\mathrm{CDCl}_{3}, 150 \mathrm{MHz}, \mathrm{ppm}\right) \delta 23.6\left(\mathrm{CH}_{2}\right), 23.8\left(\mathrm{CH}_{2}\right)$, $23.92\left(\mathrm{CH}_{2}\right), 23.95\left(\mathrm{CH}_{2}\right), 24.9\left(\mathrm{CH}_{2}\right), 25.0\left(\mathrm{CH}_{2}\right), 35.1\left(\mathrm{CH}_{2}\right), 35.8\left(\mathrm{CH}_{2}\right), 37.2\left(\mathrm{CH}_{2}\right), 38.1\left(\mathrm{CH}_{2}\right)$, $52.0\left(\mathrm{CH}_{3}, \mathrm{C}-8\right.$ or $\left.\mathrm{C}-8^{\prime}\right), 52.1\left(\mathrm{CH}_{3}, \mathrm{C}-8\right.$ or $\left.\mathrm{C} 8^{\prime}\right), 61.9\left(\mathrm{CH}_{3}, 6^{\prime}-\mathrm{OMe}\right), 70.7(\mathrm{CH}, \mathrm{C}-3), 72.4\left(\mathrm{CH}, \mathrm{C}-3^{\prime}\right)$, $73.4(\mathrm{CH}, \mathrm{C}-4), 75.4\left(\mathrm{CH}, \mathrm{C}-5^{\prime}\right), 75.7\left(\mathrm{CH}, \mathrm{C}-4^{\prime}\right), 76.6(\mathrm{CH}, \mathrm{C}-6), 80.0\left(\mathrm{CH}, \mathrm{C}-6^{\prime}\right), 82.0(\mathrm{CH}, \mathrm{C}-5), 110.8(\mathrm{Cq})$, $111.7(\mathrm{Cq}), 130.5\left(\mathrm{CH}, \mathrm{C}-2^{\prime}\right), 132.7$ (Cq, C-1), $135.4(\mathrm{CH}, \mathrm{C}-2), 135.9$ (Cq, C-1'), 166.3 (Cq, C-7'), 166.7 (Cq, C-7); HRMS $m / z$ calcd for $\mathrm{C}_{29} \mathrm{H}_{40} \mathrm{O}_{11}(\mathrm{M})^{+} 564.2571$, found 564.2570 .

(+)-19 (80 mg, 44\%) was prepared from (+)-10 (86.0 mg, $0.29 \mathrm{mmol})$ and $(+)-\mathbf{1 1}(86.2 \mathrm{mg}, 0.29 \mathrm{mmol})$ : white powder; $\mathrm{mp} 165-169^{\circ} \mathrm{C}:[\alpha]_{\mathrm{D}}^{20}+69.0\left(c \quad 0.75, \mathrm{CHCl}_{3}\right)$; IR $(\mathrm{KBr}) v_{\max } 3408(\mathrm{OH}), 1725(\mathrm{C}=\mathrm{O})$, $1440(\mathrm{C}=\mathrm{C}) \mathrm{cm}^{-1} ;{ }^{1} \mathrm{H}-\mathrm{NMR}\left(\mathrm{CDCl}_{3}, 400 \mathrm{MHz}, \mathrm{ppm}\right) \delta 1.30-1.80(20 \mathrm{H}, \mathrm{m}), 3.72(3 \mathrm{H}, \mathrm{s}, \mathrm{OMe}), 3.79(6 \mathrm{H}, \mathrm{s}$, $2 \times \mathrm{COOMe}), 3.91(1 \mathrm{H}, \mathrm{dd}, J=8.9,6.2 \mathrm{~Hz}), 4.05(1 \mathrm{H}, \mathrm{br} \mathrm{d}, J=8.1 \mathrm{~Hz}), 4.13(1 \mathrm{H}, \mathrm{dd}, J=8.4,5.9 \mathrm{~Hz})$, $4.25(1 \mathrm{H}, \mathrm{br} \mathrm{d}, J=6.5 \mathrm{~Hz}), 4.41(1 \mathrm{H}, \mathrm{br} \mathrm{d}, J=7.8 \mathrm{~Hz}), 4.59-4.65(2 \mathrm{H}, \mathrm{m}), 4.82-4.86(1 \mathrm{H}, \mathrm{m}), 5.00-5.03$ $(1 \mathrm{H}, \mathrm{m}), 6.41(1 \mathrm{H}, \mathrm{m}), 6.60(1 \mathrm{H}, \mathrm{m}) ;{ }^{13} \mathrm{C}-\mathrm{NMR}\left(\mathrm{CDCl}_{3}, 100 \mathrm{MHz}, \mathrm{ppm}\right) \delta 23.6,23.7,23.89,23.92,24.9$, $24.9,35.1,35.8,37.2,38.1,52.0,52.1,61.9,70.6,72.3,73.4,75.4,75.6,76.6,80.0,82.0,110.8,111.6,130.5$, 132.6, 135.4, 135.8, 166.2, 166.6; HREIMS $\mathrm{m} / z$ calcd for $\mathrm{C}_{29} \mathrm{H}_{40} \mathrm{O}_{11}(\mathrm{M})^{+}$564.2571, found 564.2568.

(-)-22 (42.8 mg, 59\%) was prepared from (-)-15 (38.6 mg, $0.13 \mathrm{mmol})$ and (-)-11 (45.1 $\mathrm{mg}$, $0.17 \mathrm{mmol})$ : oil; $[\alpha]_{\mathrm{D}} 22.5-44.9\left(\right.$ c $\left.0.73, \mathrm{CHCl}_{3}\right)$; IR (film) $v_{\max } 3445(\mathrm{OH}), 1717(\mathrm{C}=\mathrm{O}), 1653(\mathrm{C}=\mathrm{C}) \mathrm{cm}^{-1}$; ${ }^{1} \mathrm{H}-\mathrm{NMR}\left(\mathrm{CDCl}_{3}, 600 \mathrm{MHz}, \mathrm{ppm}\right) \delta 1.21-1.74(20 \mathrm{H}, \mathrm{m}), 3.31$ (3H, s, OMe), 3.76 (3H, s, COOMe), $3.82(3 \mathrm{H}, \mathrm{s}, \mathrm{COOMe}), 3.87\left(1 \mathrm{H}, \mathrm{br} \mathrm{t}, J=8.5 \mathrm{~Hz}, \mathrm{H}-5^{\prime}\right), 4.07(1 \mathrm{H}, \mathrm{dd}, J=4.1,3.0 \mathrm{~Hz}, \mathrm{H}-5), 4.20(1 \mathrm{H}, \mathrm{d}$, $\left.J=7.1 \mathrm{~Hz}, \mathrm{H}-6^{\prime}\right), 4.21\left(1 \mathrm{H}, \mathrm{dd}, J=9.1,6.8 \mathrm{~Hz}, \mathrm{H}-4^{\prime}\right), 4.51-4.53(1 \mathrm{H}, \mathrm{m}, \mathrm{H}-4), 4.65(1 \mathrm{H}, \mathrm{ddd}, J=6.7,3.8$, $\left.1.1 \mathrm{~Hz}, \mathrm{H}-3^{\prime}\right), 4.73(1 \mathrm{H}, \mathrm{dd}, J=5.9,3.8 \mathrm{~Hz}, \mathrm{H}-3), 4.82(1 \mathrm{H}, \mathrm{s},-\mathrm{OH}), 4.83(1 \mathrm{H}, \mathrm{d}, J=4.1 \mathrm{~Hz}, \mathrm{H}-6), 6.71(1 \mathrm{H}$, $\left.\mathrm{dd}, J=3.8,2.0 \mathrm{~Hz}, \mathrm{H}-2^{\prime}\right), 6.97(1 \mathrm{H}, \mathrm{dd}, J=3.8,0.9 \mathrm{~Hz}, \mathrm{H}-2) ;{ }^{13} \mathrm{C}-\mathrm{NMR}\left(\mathrm{CDCl}_{3}, 150 \mathrm{MHz}, \mathrm{ppm}\right) \delta 23.6$ $\left(\mathrm{CH}_{2}\right), 23.7\left(\mathrm{CH}_{2}\right), 23.9\left(\mathrm{CH}_{2}\right), 25.0\left(\mathrm{CH}_{2}\right), 35.2\left(\mathrm{CH}_{2}\right), 35.7\left(\mathrm{CH}_{2}\right), 37.1\left(\mathrm{CH}_{2}\right), 37.8\left(\mathrm{CH}_{2}\right), 52.0\left(\mathrm{CH}_{3}\right.$, COOMe), $52.4\left(\mathrm{CH}_{3}, \mathrm{COOMe}\right), 56.1\left(\mathrm{CH}_{3}, 6-\mathrm{OMe}\right), 68.5(\mathrm{CH}, \mathrm{C}-6), 70.8\left(\mathrm{CH}, \mathrm{C}-3^{\prime}\right), 72.7(\mathrm{CH}, \mathrm{C}-3)$, $73.1\left(\mathrm{CH}, \mathrm{C}-5^{\prime}\right), 73.5(\mathrm{CH}, \mathrm{C}-4), 76.0\left(\mathrm{CH}, \mathrm{C}-4^{\prime}\right), 78.4(\mathrm{CH}, \mathrm{C}-5), 78.5\left(\mathrm{CH}, \mathrm{C}-6^{\prime}\right), 111.6(\mathrm{Cq}), 112.0(\mathrm{Cq})$, 
129.1 (Cq, C-1), 132.4 (CH, C-2'), 135.7 (Cq, C-1'), 140.5 (CH, C-2), 166.3 (Cq, C-7'), 167.0 (Cq, C-7); HREIMS $\mathrm{m} / z$ calcd for $\mathrm{C}_{29} \mathrm{H}_{40} \mathrm{O}_{11}(\mathrm{M})^{+} 564.2571$, found 564.2573.

(+)-22 (41.5 mg, 63\%) was prepared from (+)-15 (34.8 mg, $0.12 \mathrm{mmol})$ and (+)-11 (34.3 mg, $0.13 \mathrm{mmol})$ : oil; $[\alpha]_{\mathrm{D}}^{21.5}+51.7\left(\right.$ c $\left.0.73, \mathrm{CHCl}_{3}\right)$; IR (film) $v_{\max } 3474(\mathrm{OH}), 1699(\mathrm{C}=\mathrm{O}), 1652(\mathrm{C}=\mathrm{C})$ $\mathrm{cm}^{-1},{ }^{1} \mathrm{H}-\mathrm{NMR}\left(\mathrm{CDCl}_{3}, 400 \mathrm{MHz}, \mathrm{ppm}\right) \delta 1.21-1.71(20 \mathrm{H}, \mathrm{m}), 3.30(3 \mathrm{H}, \mathrm{s}, \mathrm{OMe}), 3.76(3 \mathrm{H}, \mathrm{s}, \mathrm{COOMe})$, $3.82(3 \mathrm{H}, \mathrm{s}, \mathrm{COOMe}), 3.87\left(1 \mathrm{H}, \mathrm{br} \mathrm{t}, J=8.8 \mathrm{~Hz}, \mathrm{H}-5^{\prime}\right), 4.07(1 \mathrm{H}, \mathrm{dd}, J=4.1,3.1 \mathrm{~Hz}, \mathrm{H}-5), 4.20(1 \mathrm{H}, \mathrm{d}$, $\left.J=6.9 \mathrm{~Hz}, \mathrm{H}-6^{\prime}\right), 4.21\left(1 \mathrm{H}, \mathrm{dd}, J=9.2,6.9 \mathrm{~Hz}, \mathrm{H}-4^{\prime}\right), 4.52(1 \mathrm{H}, \mathrm{dd}, J=5.7,2.5 \mathrm{~Hz}, \mathrm{H}-4), 4.66(1 \mathrm{H}, \mathrm{br} \mathrm{dd}$, $\left.J=6.3,3.7 \mathrm{~Hz}, \mathrm{H}-3^{\prime}\right), 4.74(1 \mathrm{H}, \mathrm{dd}, J=5.9,3.7 \mathrm{~Hz}, \mathrm{H}-3), 4.83(1 \mathrm{H}, \mathrm{d}, J=3.9 \mathrm{~Hz}, \mathrm{H}-6), 4.85(1 \mathrm{H}, \mathrm{br} \mathrm{s}$, -OH), $6.72\left(1 \mathrm{H}, \mathrm{dd}, J=3.8,2.0 \mathrm{~Hz}, \mathrm{H}-2^{\prime}\right), 6.98(1 \mathrm{H}, \mathrm{br} \mathrm{d}, J=3.5 \mathrm{~Hz}, \mathrm{H}-2) ;{ }^{13} \mathrm{C}-\mathrm{NMR}\left(\mathrm{CDCl}_{3}, 100 \mathrm{MHz}\right.$, ppm) $\delta 23.55,23.62,23.89,23.91,25.0,35.2,35.7,37.0,37.8,52.0,52.4,56.1,68.4,70.8,72.7,73.0,73.4$, $75.9,78.3,78.5,110.6,112.0,129.0,132.4,135.7,140.5,166.2,166.9$; HREIMS $m / z$ calcd for $\mathrm{C}_{29} \mathrm{H}_{40} \mathrm{O}_{11}$ $(\mathrm{M})^{+}$564.2571, found 564.2571 .

\subsection{Inversion of Configuration at $C 5^{\prime}$}

General procedure (synthesis of (+)-13, Scheme 1): A microwave vial containing a $\mathrm{CH}_{2} \mathrm{Cl}_{2}$ solution $(2 \mathrm{~mL})$ of $(-)-\mathbf{1 2}(47.6 \mathrm{mg}, 0.084 \mathrm{mmol})$ was treated with DMP $(77.0 \mathrm{mg}, 0.23 \mathrm{mmol})$ at $0{ }^{\circ} \mathrm{C}$, sealed, and irradiated in the MW reactor at $80^{\circ} \mathrm{C}$ for $2.5 \mathrm{~h}$. After cooling, the reaction mixture was treated with aqueous saturated (sat.) $\mathrm{Na}_{2} \mathrm{~S}_{2} \mathrm{O}_{3}(20 \mathrm{~mL})$ and saturated aqueous $\mathrm{NaHCO}_{3}(10 \mathrm{~mL})$ and extracted with tert-butyl methyl ether $(3 \times 20 \mathrm{~mL})$. The combined organic layers were washed with brine $(30 \mathrm{~mL})$ and water $(30 \mathrm{~mL})$, dried over $\mathrm{MgSO}_{4}$, filtered, and concentrated in a vacuum to afford a crude residue containing the desired ketone. To a solution of $\mathrm{NaBH}_{4}(1.0 \mathrm{mg}, 0.026 \mathrm{mmol})$ in $\mathrm{MeOH}(0.6 \mathrm{~mL})$, a solution of the crude residue in $\mathrm{MeOH}(2.0 \mathrm{~mL})$ at $0{ }^{\circ} \mathrm{C}$ was added dropwise. After $30 \mathrm{~min}$ of stirring, the reaction mixture was treated with saturated aqueous $\mathrm{NH}_{4} \mathrm{Cl}(30 \mathrm{~mL})$ and extracted with $\mathrm{CH}_{2} \mathrm{Cl}_{2}$ $(3 \times 30 \mathrm{~mL})$. The combined organic layers were washed with brine $(30 \mathrm{~mL})$, dried over $\mathrm{MgSO}_{4}$, filtered, and concentrated in a vacuum to afford the second crude residue, which was purified by silica gel column chromatography (eluent = hexane:EtOAc, 2:1 v/v) to afford (+)-13 (22.9 mg, 48\% from (-)-12) as a colorless oil.

(+)-13: oil; $[\alpha]_{\mathrm{D}}^{20}+26.8$ ( c 1.03, $\left.\mathrm{CHCl}_{3}\right)$; IR (film) $v_{\max } 3414(\mathrm{OH}), 1721(\mathrm{C}=\mathrm{O}), 1658(\mathrm{C}=\mathrm{C}) \mathrm{cm}^{-1}$; ${ }^{1} \mathrm{H}-\mathrm{NMR}\left(\mathrm{CDCl}_{3}, 300 \mathrm{MHz}, \mathrm{ppm}\right) \delta 1.20-1.90(20 \mathrm{H}, \mathrm{m}), 3.39$ (3H, s, 6'-OMe), 3.70-3.80 (1H, overlapped, $\mathrm{H}-3), 3.75(3 \mathrm{H}, \mathrm{s}, \mathrm{COOMe}), 3.85(3 \mathrm{H}, \mathrm{s}, \mathrm{COOMe}), 4.18\left(1 \mathrm{H}, \mathrm{dd}, J=5.9,3.2 \mathrm{~Hz}, \mathrm{H}-5^{\prime}\right), 4.31(1 \mathrm{H}, \mathrm{d}$, $J=5.9 \mathrm{~Hz}, \mathrm{H}-5), 4.44-4.48(1 \mathrm{H}, \mathrm{m}, \mathrm{H}-6), 4.55\left(1 \mathrm{H}, \mathrm{d}, J=4.9 \mathrm{~Hz}, \mathrm{H}-4^{\prime}\right), 4.63(1 \mathrm{H}, \mathrm{dd}, J=5.5,3.5 \mathrm{~Hz}$, H-6'), 4.68-4.74 (2H, m, H-3', 4), $4.81\left(1 \mathrm{H}, \mathrm{d}, J=11.7 \mathrm{~Hz}, 5^{\prime}-\mathrm{OH}\right), 6.72(1 \mathrm{H}, \mathrm{br} \mathrm{s}, \mathrm{H}-2), 6.75(1 \mathrm{H}, \mathrm{dd}$, $\left.J=3.2,0.6 \mathrm{~Hz}, \mathrm{H}-2^{\prime}\right) ;{ }^{13} \mathrm{C}-\mathrm{NMR}\left(\mathrm{CDCl}_{3}, 75 \mathrm{MHz}, \mathrm{ppm}\right) \delta 23.6\left(\mathrm{CH}_{2}\right), 23.7\left(\mathrm{CH}_{2}\right), 23.8\left(\mathrm{CH}_{2}\right), 23.9\left(\mathrm{CH}_{2}\right)$, $24.9\left(\mathrm{CH}_{2}\right), 25.0\left(\mathrm{CH}_{2}\right), 34.0\left(\mathrm{CH}_{2}\right), 35.7\left(\mathrm{CH}_{2}\right), 36.0\left(\mathrm{CH}_{2}\right), 37.6\left(\mathrm{CH}_{2}\right), 51.9\left(\mathrm{CH}_{3}, \mathrm{COOMe}\right), 52.3\left(\mathrm{CH}_{3}\right.$, $\mathrm{COOMe}), 59.3\left(\mathrm{CH}_{3}, 6^{\prime}-\mathrm{OMe}\right), 68.0\left(\mathrm{CH}, \mathrm{C}-5^{\prime}\right), 71.5(\mathrm{CH}, \mathrm{C}-3), 72.4\left(\mathrm{CH}, \mathrm{C}-3^{\prime}\right), 73.2\left(2 \times \mathrm{CH}, \mathrm{C} 4, \mathrm{C}-6^{\prime}\right)$, $74.6\left(\mathrm{CH}, \mathrm{C}-6\right.$ or C-4'), $74.7\left(\mathrm{CH}, \mathrm{C}-6\right.$ or C-4'), $79.7(\mathrm{CH}, \mathrm{C}-5), 110.8(\mathrm{Cq}), 111.7(\mathrm{Cq}), 129.7\left(\mathrm{Cq}, \mathrm{C}-1^{\prime}\right)$, $131.3(\mathrm{Cq}, \mathrm{C}-1), 137.5(\mathrm{CH}, \mathrm{C}-2$ or C-2'), 137.7 (CH, C-2 or C-2'), 166.6 (Cq, C-7 or C-7'), 166.7 (Cq, C-7 or C-7'); HREIMS $\mathrm{m} / z$ calcd for $\mathrm{C}_{29} \mathrm{H}_{40} \mathrm{O}_{11}(\mathrm{M})^{+} 564.2571$, found 564.2570 .

$(-)-13(46.3 \mathrm{mg})$ was prepared in 54\% yield from $(+)-\mathbf{1 2}(85.6 \mathrm{mg}, 0.15 \mathrm{mmol})$ : oil; $[\alpha]_{\mathrm{D}}^{20}-28.3$ (c 0.745, $\left.\mathrm{CHCl}_{3}\right)$; IR (film) $v_{\max } 3363(\mathrm{OH}), 1720(\mathrm{C}=\mathrm{O}), 1655(\mathrm{C}=\mathrm{C}) \mathrm{cm}^{-1},{ }^{1} \mathrm{H}-\mathrm{NMR}\left(\mathrm{CDCl}_{3}, 600 \mathrm{MHz}\right.$, ppm) $\delta 1.36-1.80(20 \mathrm{H}, \mathrm{m}), 3.39(3 \mathrm{H}, \mathrm{s}, \mathrm{OMe}), 3.73-3.75\left(1 \mathrm{H}, \mathrm{m}, \mathrm{H}-5^{\prime}\right), 3.74(3 \mathrm{H}, \mathrm{s}, \mathrm{COOMe}), 3.84(3 \mathrm{H}, \mathrm{s}$, COOMe), $4.18\left(1 \mathrm{H}, \mathrm{dd}, J=5.9,3.5 \mathrm{~Hz}, \mathrm{H}-5^{\prime}\right), 4.31(1 \mathrm{H}, \mathrm{d}, J=6.1 \mathrm{~Hz}, \mathrm{H}-5), 4.46(1 \mathrm{H}, \mathrm{ddd}, J=6.4,5.6$, $1.1 \mathrm{~Hz}, \mathrm{H}-6), 4.55\left(1 \mathrm{H}, \mathrm{d}, J=5.0 \mathrm{~Hz}, \mathrm{H}-4^{\prime}\right), 4.62\left(1 \mathrm{H}, \mathrm{ddd}, J=5.6,3.2,0.9 \mathrm{~Hz}, \mathrm{H}-3^{\prime}\right), 4.70(1 \mathrm{H}, \mathrm{ddd}, J=6.4$, $3.2,0.9 \mathrm{~Hz}, \mathrm{H}-3), 4.72(1 \mathrm{H}, \mathrm{dd}, J=6.4,3.5 \mathrm{~Hz}, \mathrm{H}-4), 6.73(1 \mathrm{H}, \mathrm{d}, J=2.3 \mathrm{~Hz}, \mathrm{H}-2), 6.75(1 \mathrm{H}, \mathrm{dd}, J=3.2$, $\left.1.2 \mathrm{~Hz}, \mathrm{H}-2^{\prime}\right) ;{ }^{13} \mathrm{C}-\mathrm{NMR}\left(\mathrm{CDCl}_{3}, 150 \mathrm{MHz}, \mathrm{ppm}\right) \delta 23.67\left(\mathrm{CH}_{2}\right), 23.73\left(\mathrm{CH}_{2}\right), 23.85\left(\mathrm{CH}_{2}\right), 23.92\left(\mathrm{CH}_{2}\right)$, $24.97\left(\mathrm{CH}_{2}\right), 25.06\left(\mathrm{CH}_{2}\right), 34.0\left(\mathrm{CH}_{2}\right), 35.8\left(\mathrm{CH}_{2}\right), 36.0\left(\mathrm{CH}_{2}\right), 37.6\left(\mathrm{CH}_{2}\right), 51.8\left(\mathrm{CH}_{3}, \mathrm{COOMe}\right), 52.3\left(\mathrm{CH}_{3}\right.$, COOMe), $59.3(\mathrm{OMe}), 68.1\left(\mathrm{CH}, \mathrm{C}-5^{\prime}\right), 71.5(\mathrm{CH}, \mathrm{C}-3), 72.4\left(\mathrm{CH}, \mathrm{C}-3^{\prime}\right), 73.2\left(\mathrm{CH}, \mathrm{C}-4\right.$ or $\left.\mathrm{C}-6^{\prime}\right), 73.3(\mathrm{CH}$, C-4 or C-6'), $74.7(\mathrm{CH}, \mathrm{C}-6$ or C-4'), $74.7(\mathrm{CH}, \mathrm{C}-6$ or C-4'), $79.6(\mathrm{CH}, \mathrm{C}-5), 110.8(\mathrm{Cq}), 111.8(\mathrm{Cq})$, $129.8\left(\mathrm{Cq}, \mathrm{C}-1^{\prime}\right), 131.3(\mathrm{Cq}, \mathrm{C}-1), 137.65(\mathrm{CH}, \mathrm{C}-2$ or C-2'), $137.70(\mathrm{CH}, \mathrm{C}-2$ or C-2'), 166.6 (Cq, C-7 or C-7'), 166.7 (Cq, C-7 or C-7'); HRMS m/z calcd for $\mathrm{C}_{29} \mathrm{H}_{40} \mathrm{O}_{11}(\mathrm{M})^{+} 564.2571$, found 564.2565. 
(+)-17 (34.8 mg, 33\%) was prepared from (-)-16 (106.6 mg, $0.19 \mathrm{mmol})$ : oil; $[\alpha]_{\mathrm{D}}^{20}+11.7(c 0.34$, $\left.\mathrm{CHCl}_{3}\right)$; IR (film) $v_{\max } 3309(\mathrm{OH}), 1718(\mathrm{C}=\mathrm{O}), 1655(\mathrm{C}=\mathrm{C}) \mathrm{cm}^{-1} ;{ }^{1} \mathrm{H}-\mathrm{NMR}$ (acetone- $\left.d_{6}, 300 \mathrm{MHz}, \mathrm{ppm}\right)$ 8 1.20-1.80 (20 H, m), 3.45 (3H, s, 6'-OMe), 3.75 (3H, s, H-8), $3.79\left(3 \mathrm{H}, \mathrm{s}, \mathrm{H}-8^{\prime}\right), 3.91-3.60\left(1 \mathrm{H}, \mathrm{m}, \mathrm{H}-5^{\prime}\right)$, $4.16(1 \mathrm{H}, \mathrm{dd}, J=4.1,2.9 \mathrm{~Hz}, \mathrm{H}-5), 4.20(1 \mathrm{H}, \mathrm{br} \mathrm{d}, J=3.8 \mathrm{~Hz}, \mathrm{H}-6), 4.52\left(1 \mathrm{H}, \mathrm{br} \mathrm{d}, J=5.3 \mathrm{~Hz}, \mathrm{H}-4^{\prime}\right)$, $4.58\left(1 \mathrm{H}, \mathrm{d}, J=3.9 \mathrm{~Hz}, \mathrm{H}-6^{\prime}\right), 4.75\left(1 \mathrm{H}, \mathrm{dd}, J=5.3,2.9 \mathrm{~Hz}, \mathrm{H}-3^{\prime}\right), 4.82(1 \mathrm{H}, \mathrm{ddd}, J=6.1,3.5,0.6 \mathrm{~Hz}, \mathrm{H}-3)$, $4.92-4.98(1 \mathrm{H}, \mathrm{m}, \mathrm{H}-4), 6.68(1 \mathrm{H}, \mathrm{d}, J=3.5 \mathrm{~Hz}, \mathrm{H}-2), 6.77\left(1 \mathrm{H}, \mathrm{d}, J=2.7 \mathrm{~Hz}, \mathrm{H}-2^{\prime}\right) ;{ }^{13} \mathrm{C}-\mathrm{NMR}$ (acetone- $d_{6}$, $75 \mathrm{MHz}, \mathrm{ppm}) \delta 23.5\left(\mathrm{CH}_{2}\right), 23.6\left(\mathrm{CH}_{2}\right), 23.7\left(\mathrm{CH}_{2}\right), 23.9\left(\mathrm{CH}_{2}\right), 24.8\left(2 \mathrm{C}, \mathrm{CH}_{2}\right), 35.2\left(\mathrm{CH}_{2}\right), 35.4\left(\mathrm{CH}_{2}\right)$, $37.2\left(\mathrm{CH}_{2}\right), 37.5\left(\mathrm{CH}_{2}\right), 51.3\left(\mathrm{CH}_{3}, \mathrm{C}-8\right), 51.5\left(\mathrm{CH}_{3}, \mathrm{C}-8^{\prime}\right), 60.5\left(\mathrm{CH}_{3}, 6^{\prime}-\mathrm{OMe}\right), 71.2\left(\mathrm{CH}, \mathrm{C}-5^{\prime}\right), 71.6(\mathrm{CH}$, C-6'), $72.3(\mathrm{CH}, \mathrm{C}-4), 72.5\left(\mathrm{CH}, \mathrm{C}-3^{\prime}\right), 72.8(\mathrm{CH}, \mathrm{C}-3), 74.9\left(2 \times \mathrm{CH}, \mathrm{C}-6,4^{\prime}\right), 79.2(\mathrm{CH}, \mathrm{C}-5), 110.8(\mathrm{Cq}$, C-1'), 111.0 (Cq, C-1), 129.4 (Cq), $130.5(\mathrm{Cq}), 136.5(\mathrm{CH}, \mathrm{C}-2), 138.2\left(\mathrm{CH}, \mathrm{C}-2^{\prime}\right), 165.9$ (Cq, C-7), 166.6 (Cq, C-7'); HREIMS $m / z$ calcd for $\mathrm{C}_{29} \mathrm{H}_{40} \mathrm{O}_{11}(\mathrm{M})^{+}$564.2571, found 564.2573.

(-)-17 (24.6 mg, 37\%) was prepared from (+)-16: oil; $[\alpha]_{\mathrm{D}}^{20}-14.5\left(c 0.36, \mathrm{CHCl}_{3}\right)$; IR (film) $v_{\max }$ $3518(\mathrm{OH}), 1717(\mathrm{C}=\mathrm{O}), 1652(\mathrm{C}=\mathrm{C}) \mathrm{cm}^{-1},{ }^{1} \mathrm{H}-\mathrm{NMR}$ (acetone- $\left.d_{6}, 600 \mathrm{MHz}, \mathrm{ppm}\right) \delta 1.25-1.70(20 \mathrm{H}, \mathrm{m})$, $3.45\left(3 \mathrm{H}, \mathrm{s}, 6^{\prime}-\mathrm{OMe}\right), 3.75(3 \mathrm{H}, \mathrm{s}, \mathrm{COOMe}), 3.79$ (3H, s, COOMe), $3.94(2 \mathrm{H}, \mathrm{ddd}, J=10.9,5.0,2.4 \mathrm{~Hz}$, H-5'), $4.15(1 \mathrm{H}, \mathrm{dd}, J=4.1,2.9 \mathrm{~Hz}, \mathrm{H}-5), 4.20(1 \mathrm{H}, \mathrm{ddd}, J=4.1,1.2,0.9 \mathrm{~Hz}, \mathrm{H}-6), 4.52(1 \mathrm{H}, \mathrm{dd}, J=5.3$, $\left.2.4 \mathrm{~Hz}, \mathrm{H}-4^{\prime}\right), 4.59\left(1 \mathrm{H}, \mathrm{d}, J=5.0 \mathrm{~Hz}, \mathrm{H}-6^{\prime}\right), 4.74\left(1 \mathrm{H}, \mathrm{ddd}, J=5.3,2.9,0.9 \mathrm{~Hz}, \mathrm{H}-3^{\prime}\right), 4.81(1 \mathrm{H}, \mathrm{ddd}, J=6.2$, 3.5, $0.6 \mathrm{~Hz}, \mathrm{H}-3), 4.95(1 \mathrm{H}, \mathrm{ddd}, J=6.1,2.9,1.5 \mathrm{~Hz}, \mathrm{H}-4), 6.68(1 \mathrm{H}, \mathrm{dd}, J=3.5,0.9 \mathrm{~Hz}, \mathrm{H}-2), 6.77(1 \mathrm{H}, \mathrm{dd}$, $\left.J=2.9,1.2 \mathrm{~Hz}, \mathrm{H}-2^{\prime}\right) ;{ }^{13} \mathrm{C}-\mathrm{NMR}$ (acetone- $\left.d_{6}, 150 \mathrm{MHz}, \mathrm{ppm}\right) \delta 24.5\left(\mathrm{CH}_{2}\right), 24.58\left(\mathrm{CH}_{2}\right), 24.65\left(\mathrm{CH}_{2}\right)$, $24.8\left(\mathrm{CH}_{2}\right), 25.75\left(\mathrm{CH}_{2}\right), 25.78\left(\mathrm{CH}_{2}\right), 36.1\left(\mathrm{CH}_{2}\right), 36.3\left(\mathrm{CH}_{2}\right), 38.2\left(\mathrm{CH}_{2}\right), 38.4\left(\mathrm{CH}_{2}\right), 52.2\left(\mathrm{CH}_{3}, \mathrm{C}-8\right)$, $52.4\left(\mathrm{CH}_{3}, \mathrm{C}-8^{\prime}\right), 61.4\left(\mathrm{CH}_{3}, 6^{\prime}-\mathrm{OMe}\right), 72.1\left(\mathrm{CH}, \mathrm{C}-5^{\prime}\right), 72.2\left(\mathrm{CH}, \mathrm{C}-6^{\prime}\right), 72.5(\mathrm{CH}, \mathrm{C}-4), 73.2\left(\mathrm{CH}, \mathrm{C}-3^{\prime}\right)$, $73.4(\mathrm{CH}, \mathrm{C} 3), 73.7(\mathrm{CH}, \mathrm{C}-6), 75.8\left(\mathrm{CH}, \mathrm{C}-4^{\prime}\right), 80.2(\mathrm{CH}, \mathrm{C}-5), 111.7(\mathrm{Cq}), 111.9(\mathrm{Cq}), 130.4\left(\mathrm{Cq}, \mathrm{C}-1^{\prime}\right)$, 131.6 (Cq, C-1), 137.3 (C, C-2), 139.1 (C, C-2'), 166.8 (Cq, C-7), 167.5 (Cq, C-7'); HREIMS m/z calcd for $\mathrm{C}_{29} \mathrm{H}_{40} \mathrm{O}_{11}(\mathrm{M})^{+}$564.2571, found 564.2571.

$(-)-20(41.8 \mathrm{mg}, 48 \%)$ was prepared from $(-)-19(87.2 \mathrm{mg}, 0.15 \mathrm{mmol})$ : white powder; $[\alpha]_{\mathrm{D}}^{20}-23.3$ (c 0.44, $\left.\mathrm{CHCl}_{3}\right)$; IR (KBr) $v_{\max } 3430(\mathrm{OH}), 1725(\mathrm{C}=\mathrm{O}), 1653(\mathrm{C}=\mathrm{C}) \mathrm{cm}^{-1},{ }^{1} \mathrm{H}-\mathrm{NMR}$ (acetone- $d_{6}, 600 \mathrm{MHz}$, ppm) $\delta 1.32-1.66(20 \mathrm{H}, \mathrm{m}), 3.73\left(3 \mathrm{H}, \mathrm{s}, 6^{\prime}-\mathrm{OMe}\right), 3.76\left(3 \mathrm{H}, \mathrm{s}, \mathrm{H}-8^{\prime}\right), 3.78(3 \mathrm{H}, \mathrm{s}, \mathrm{H}-8), 3.88(1 \mathrm{H}, \mathrm{ddd}$, $\left.J=12.6,5.0,2.9 \mathrm{~Hz}, \mathrm{H}-5^{\prime}\right), 4.08(1 \mathrm{H}, \mathrm{dd}, J=8.5,2.3 \mathrm{~Hz}, \mathrm{H}-5), 4.22(1 \mathrm{H}, \mathrm{dt}, J=8.5,1.7 \mathrm{~Hz}, \mathrm{H}-6), 4.49-4.51$ $\left(1 \mathrm{H}, \mathrm{m}, \mathrm{H}-4^{\prime}\right), 4.63\left(1 \mathrm{H}, \mathrm{d}, J=5.0 \mathrm{~Hz}, \mathrm{H}-6^{\prime}\right), 4.66\left(1 \mathrm{H}, \mathrm{d}, J=12.6 \mathrm{~Hz}, 5^{\prime}-\mathrm{OH}\right), 4.72(1 \mathrm{H}, \mathrm{ddd}, J=5.6,3.2$, $\left.1.2 \mathrm{~Hz}, \mathrm{H}-3^{\prime}\right), 4.74(1 \mathrm{H}, \mathrm{ddd}, J=5.0 .2 .9,1.7 \mathrm{~Hz}, \mathrm{H}-3), 4.98(1 \mathrm{H}, \mathrm{br} \mathrm{ddd}, J=5.0,2.0,1.5 \mathrm{~Hz}, \mathrm{H}-4), 6.31(1 \mathrm{H}$, $\mathrm{dt}, J=3.0,1.4 \mathrm{~Hz}, \mathrm{H}-2), 6.70\left(1 \mathrm{H}, \mathrm{dd}, J=2.9,1.8 \mathrm{~Hz}, \mathrm{H}-2^{\prime}\right) ;{ }^{13} \mathrm{C}-\mathrm{NMR}$ (acetone- $\left.d_{6}, 150 \mathrm{MHz}, \mathrm{ppm}\right) \delta$ 23.60 $\left(\mathrm{CH}_{2}\right), 23.61\left(\mathrm{CH}_{2}\right), 23.8\left(\mathrm{CH}_{2}\right), 24.78\left(\mathrm{CH}_{2}\right), 24.81\left(\mathrm{CH}_{2}\right), 35.4\left(\mathrm{CH}_{2}\right), 35.5\left(\mathrm{CH}_{2}\right), 37.2\left(\mathrm{CH}_{2}\right)$, $37.5\left(\mathrm{CH}_{2}\right), 51.2\left(\mathrm{CH}_{3}, \mathrm{C}-8\right.$ or C-8'), $51.5\left(\mathrm{CH}_{3}, \mathrm{C}-8\right.$ or $\left.\mathrm{C}-8^{\prime}\right), 61.8\left(\mathrm{CH}_{3}, 6^{\prime}-\mathrm{OMe}\right), 68.5\left(\mathrm{CH}, \mathrm{C}-5^{\prime}\right), 71.2(\mathrm{CH}$, C-6'), $72.30(\mathrm{CH}, \mathrm{C}-3), 72.34\left(\mathrm{CH}, \mathrm{C}-3^{\prime}\right), 72.9(\mathrm{CH}, \mathrm{C}-6), 75.2(\mathrm{CH}, \mathrm{C}-4), 77.0\left(\mathrm{CH}, \mathrm{C}-4^{\prime}\right), 81.4(\mathrm{CH}, \mathrm{C}-5)$, $109.7(\mathrm{Cq}), 110.8(\mathrm{Cq}), 129.4\left(\mathrm{Cq}, \mathrm{C}-1^{\prime}\right), 132.9(\mathrm{CH}, \mathrm{C}-1), 135.3(\mathrm{Cq}, \mathrm{C}-2), 137.8\left(\mathrm{CH}, \mathrm{C}-2^{\prime}\right), 166.1(\mathrm{Cq}$, C-7'), 166.7 (Cq, C-7); HRMS m/z calcd for $\mathrm{C}_{29} \mathrm{H}_{40} \mathrm{O}_{11}(\mathrm{M})^{+}$564.2570, found 564.2570.

(+)-20 (44.6 mg, 51\%) was prepared from (+)-19 (79.3 mg, $0.14 \mathrm{mmol}):$ oil; $[\alpha]_{\mathrm{D}}^{20}+15.6($ c 0.27 , $\left.\mathrm{CHCl}_{3}\right)$; IR (film) $v_{\max } 3419(\mathrm{OH}), 1725(\mathrm{C}=\mathrm{O}), 1652(\mathrm{C}=\mathrm{C}) \mathrm{cm}^{-1}$; ${ }^{1} \mathrm{H}-\mathrm{NMR}$ (acetone- $d_{6}, 400 \mathrm{MHz}, \mathrm{ppm}$ ) 8 1.32-1.66 (20H, m), $3.74(3 \mathrm{H}, \mathrm{s}, \mathrm{OMe}), 3.76\left(3 \mathrm{H}, \mathrm{s}, \mathrm{C}^{7} \mathrm{OOMe}\right), 3.78\left(3 \mathrm{H}, \mathrm{s}, \mathrm{C}^{7^{\prime}} \mathrm{OOMe}\right), 3.88(1 \mathrm{H}, \mathrm{ddd}$, $J=12.3,4.9,2.9 \mathrm{~Hz}), 4.10(1 \mathrm{H}, \mathrm{dd}, J=8.6,2.4 \mathrm{~Hz}), 4.22(1 \mathrm{H}, \mathrm{dt}, J=8.4,1.8 \mathrm{~Hz}), 4.48-4.52(1 \mathrm{H}, \mathrm{m})$, $4.63(1 \mathrm{H}, \mathrm{d}, J=4.7 \mathrm{~Hz}), 4.67(1 \mathrm{H}, \mathrm{d}, J=12.5 \mathrm{~Hz}), 4.71-4.76(2 \mathrm{H}, \mathrm{m}), 4.98-5.00(1 \mathrm{H}, \mathrm{m}), 6.30(1 \mathrm{H}, \mathrm{br} \mathrm{s})$, $6.70(1 \mathrm{H}, \mathrm{dd}, J=3.1,1.0 \mathrm{~Hz}) ;{ }^{13} \mathrm{C}-\mathrm{NMR}$ (acetone- $\left.d_{6}, 100 \mathrm{MHz}, \mathrm{ppm}\right) \delta 23.58,23.59,23.8,24.75,24.78$, $35.4,35.5,37.2,37.4,51.2,51.4,61.8,68.5,71.1,72.29,72.33,72.8,75.2,77.0,81.4,109.7,110.8,129.3,132.9$, 135.3, 137.8, 166.0, 166.6; HREIMS $m / z$ calcd for $\mathrm{C}_{29} \mathrm{H}_{40} \mathrm{O}_{11}(\mathrm{M})^{+} 564.2570$, found 564.2573.

(+)-23 (7.5 mg, 53\%) was prepared from $(-)-22(14.1 \mathrm{mg}, 0.025 \mathrm{mmol}):$ oil: $[\alpha]_{\mathrm{D}}^{22}+24.6($ c 0.26 , $\left.\mathrm{CHCl}_{3}\right)$; IR (film) $v_{\max } 3445(\mathrm{OH}), 1722(\mathrm{C}=\mathrm{O}), 1437(\mathrm{C}=\mathrm{C}) \mathrm{cm}^{-1} ;{ }^{1} \mathrm{H}-\mathrm{NMR}\left(\mathrm{CDCl}_{3}, 600 \mathrm{MHz}, \mathrm{ppm}\right) \delta$ 1.29-1.71 (20H, m), $3.44(3 \mathrm{H}, \mathrm{s}, \mathrm{OMe}), 3.87\left(1 \mathrm{H}, \mathrm{br} \mathrm{t}, J=3.5 \mathrm{~Hz}, \mathrm{H}-5^{\prime}\right), 3.78(3 \mathrm{H}, \mathrm{s}, \mathrm{COOMe}), 3.82(3 \mathrm{H}, \mathrm{s}$, COOMe), $3.99(1 \mathrm{H}, \mathrm{dd}, J=4.7,3.0 \mathrm{~Hz}, \mathrm{H}-5), 4.35(1 \mathrm{H}, \mathrm{dd}, J=5.9,3.0 \mathrm{~Hz}, \mathrm{H}-4), 4.57(1 \mathrm{H}, \mathrm{dd}, J=5.2$, $\left.3.2 \mathrm{~Hz}, \mathrm{H}-4^{\prime}\right), 4.62(1 \mathrm{H}, \mathrm{dd}, J=5.3,3.5 \mathrm{~Hz}, \mathrm{H}-3), 4.64\left(1 \mathrm{H}, \mathrm{d}, J=5.3 \mathrm{~Hz}, \mathrm{H}-6^{\prime}\right), 4.72(1 \mathrm{H}, \mathrm{dd}, J=5.9$, $\left.3.5 \mathrm{~Hz}, \mathrm{H}-3^{\prime}\right), 4.76(1 \mathrm{H}, \mathrm{d}, J=4.4 \mathrm{~Hz}, \mathrm{H}-6), 6.86(1 \mathrm{H}, \mathrm{dd}, J=3.5,0.9 \mathrm{~Hz}, \mathrm{H}-2), 6.93(1 \mathrm{H}, \mathrm{dd}, J=3.8$, $\left.0.9 \mathrm{~Hz}, \mathrm{H}-2^{\prime}\right) ;{ }^{13} \mathrm{C}-\mathrm{NMR}\left(\mathrm{CDCl}_{3}, 150 \mathrm{MHz}, \mathrm{ppm}\right) \delta 23.66\left(\mathrm{CH}_{2}\right), 23.73\left(\mathrm{CH}_{2}\right), 23.8\left(\mathrm{CH}_{2}\right), 23.9\left(\mathrm{CH}_{2}\right)$, 
$25.0\left(\mathrm{CH}_{2}\right), 35.4\left(\mathrm{CH}_{2}\right), 35.5\left(\mathrm{CH}_{2}\right), 37.2\left(\mathrm{CH}_{2}\right), 52.25\left(\mathrm{CH}_{3}, \mathrm{COOMe}\right), 52.31\left(\mathrm{CH}_{3}, \mathrm{COOMe}\right), 57.9\left(\mathrm{CH}_{3}\right.$, 6-OMe), $68.4\left(\mathrm{CH}, \mathrm{C}-5^{\prime}\right), 69.3(\mathrm{CH}, \mathrm{C}-6), 70.9\left(\mathrm{CH}, \mathrm{C}-6^{\prime}\right), 72.2\left(\mathrm{CH}, \mathrm{C}-3^{\prime}\right), 72.6(\mathrm{CH}, \mathrm{C}-3), 73.8(\mathrm{CH}, \mathrm{C}-4)$, $74.6\left(\mathrm{CH}, \mathrm{C}-4^{\prime}\right), 76.2(\mathrm{CH}, \mathrm{C}-5), 110.85(\mathrm{Cq}), 111.88(\mathrm{Cq}), 129.8(\mathrm{Cq}, \mathrm{C}-1), 130.4\left(\mathrm{Cq}, \mathrm{C}-1^{\prime}\right), 139.0(\mathrm{CH}$, C-2'), $139.0(\mathrm{CH}, \mathrm{C}-2), 166.9$ (Cq, C-7'), 167.1 (Cq, C-7); HREIMS m/z calcd for $\mathrm{C}_{29} \mathrm{H}_{40} \mathrm{O}_{11}(\mathrm{M})^{+} 564.2571$, found 564.2567 .

(-)-23 (5.5 mg, 25\%) was prepared from (+)-22 (22.1 mg, $0.039 \mathrm{mmol}):$ oil: $[\alpha]_{\mathrm{D}}^{20}-29.7$ (c 0.26, $\left.\mathrm{CHCl}_{3}\right)$; IR (film) $v_{\max } 3495(\mathrm{OH}), 1717(\mathrm{C}=\mathrm{O}), 1436(\mathrm{C}=\mathrm{C}) \mathrm{cm}^{-1},{ }^{1} \mathrm{H}-\mathrm{NMR}\left(\mathrm{CDCl}_{3}, 400 \mathrm{MHz}, \mathrm{ppm}\right)$ ઈ 1.25-1.72 (20H, m), $3.44(3 \mathrm{H}, \mathrm{s}, \mathrm{OMe}), 3.75-3.79\left(1 \mathrm{H}, \mathrm{m}, \mathrm{H}-5^{\prime}\right), 3.78(3 \mathrm{H}, \mathrm{s}, \mathrm{COOMe}), 3.82(3 \mathrm{H}, \mathrm{s}$, COOMe), $3.99(1 \mathrm{H}, \mathrm{dd}, J=4.3,2.9 \mathrm{~Hz}, \mathrm{H}-5), 4.35(1 \mathrm{H}, \mathrm{dd}, J=5.6,2.7 \mathrm{~Hz}, \mathrm{H}-4), 4.58(1 \mathrm{H}, \mathrm{dd}, J=5.6$, $\left.3.2 \mathrm{~Hz}, \mathrm{H}-4^{\prime}\right), 4.62-4.65\left(2 \mathrm{H}\right.$, overlapped, H-3, H-6'), $4.72\left(1 \mathrm{H}, \mathrm{dd}, J=5.9,3.6 \mathrm{~Hz}, \mathrm{H}-3^{\prime}\right), 4.76(1 \mathrm{H}, \mathrm{d}$, $J=3.4 \mathrm{~Hz}, \mathrm{H}-6), 6.86(1 \mathrm{H}$, br d, $J=3.0 \mathrm{~Hz}, \mathrm{H}-2), 6.94\left(1 \mathrm{H}\right.$, br d, $\left.J=3.5 \mathrm{~Hz}, \mathrm{H}-2^{\prime}\right) ;{ }^{13} \mathrm{C}-\mathrm{NMR}\left(\mathrm{CDCl}_{3}\right.$, $100 \mathrm{MHz}, \mathrm{ppm}) \delta 23.66,23.74,23.8,23.9,25.0,35.4,35.5,37.2,52.29,52.35,57.9,68.4,69.3,70.8,72.2$, 72.7, 73.8, 74.6, 76.1,110.9, 111.9, 111.9, 129.8, 130.4, 139.0, 139.1, 166.9, 167.1; HREIMS $\mathrm{m} / \mathrm{z}$ calcd for $\mathrm{C}_{29} \mathrm{H}_{40} \mathrm{O}_{11}(\mathrm{M})^{+}$564.2571, found 564.2573.

\subsection{Deprotection to Carbadisaccharides}

General procedure (synthesis of (+)-6 from (+)-13, Scheme 1): A microwave vial containing a methanolic solution $(0.5 \mathrm{~mL})$ of $(+)-\mathbf{1 3}(36.0 \mathrm{mg}, 0.064 \mathrm{mmol})$ was charged with TFA $(4.5 \mathrm{~mL})$ at $0{ }^{\circ} \mathrm{C}$, sealed, and irradiated in the MW reactor at $80^{\circ} \mathrm{C}$ for $5.5 \mathrm{~h}$. After cooling, the reaction mixture was concentrated in a vacuum to afford a crude residue that was purified by silica gel column chromatography (eluent $=\mathrm{MeOH}: \mathrm{CH}_{2} \mathrm{Cl}_{2}, 2: 8 \mathrm{v} / \mathrm{v}$ ) to afford (+)-6 $(6.6 \mathrm{mg}, 26 \%)$.

(+)-6:oil; $[\alpha]_{\mathrm{D}}^{20}+57.8\left(\right.$ c 0.37, EtOH); IR (film) $v_{\max } 3384(\mathrm{OH}), 1718(\mathrm{C}=\mathrm{O}), 1653(\mathrm{C}=\mathrm{C}) \mathrm{cm}^{-1}$; ${ }^{1} \mathrm{H}-\mathrm{NMR}$ (acetone- $\left.d_{6}, 400 \mathrm{MHz}, \mathrm{ppm}\right) \delta 3.48\left(3 \mathrm{H}, \mathrm{s}, 6^{\prime}-\mathrm{OMe}\right), 3.75\left(1 \mathrm{H}\right.$, overlapped, $\left.\mathrm{H}-5^{\prime}\right) 3.75(3 \mathrm{H}, \mathrm{s}$, COOMe), $3.80(3 \mathrm{H}, \mathrm{s}, \mathrm{COOMe}), 3.95\left(1 \mathrm{H}, \mathrm{br} \mathrm{d}, J=3.1 \mathrm{~Hz}, \mathrm{H}-4^{\prime}\right), 4.03\left(1 \mathrm{H}, \mathrm{br} \mathrm{s}, \mathrm{H}-4^{\prime}\right), 4.13(1 \mathrm{H}, \mathrm{br} \mathrm{d}$, $J=4.7 \mathrm{~Hz}, \mathrm{H}-3), 4.22(1 \mathrm{H}$, overlapped, H-3'), $4.24(1 \mathrm{H}, \mathrm{br} \mathrm{d}, J=2.4 \mathrm{~Hz}, \mathrm{H}-5), 4.35(1 \mathrm{H}, \mathrm{d}, J=3.1 \mathrm{~Hz}$, H-6), $4.52\left(1 \mathrm{H}, \mathrm{d}, J=3.9 \mathrm{~Hz}, \mathrm{H}-6^{\prime}\right), 6.69\left(1 \mathrm{H}, \mathrm{br} \mathrm{s}, \mathrm{H}-2^{\prime}\right), 6.88(1 \mathrm{H}, \mathrm{d}, J=4.5 \mathrm{~Hz}, \mathrm{H}-2) ;{ }^{13} \mathrm{C}-\mathrm{NMR}$ (acetone- $\left.d_{6}, 100 \mathrm{MHz}, \mathrm{ppm}\right) \delta 52.1\left(\mathrm{CH}_{3}, \mathrm{C}-8\right), 52.4\left(\mathrm{CH}_{3}, \mathrm{C}-8^{\prime}\right), 58.6\left(\mathrm{CH}_{3}, 66^{\prime}-\mathrm{OMe}\right), 65.9(\mathrm{CH}, \mathrm{C}-3)$, $68.0(\mathrm{CH}, \mathrm{C}-4), 69.2\left(\mathrm{CH}, \mathrm{C}-3^{\prime}\right), 70.5\left(\mathrm{CH}, \mathrm{C}-5^{\prime}\right), 72.4\left(\mathrm{CH}, \mathrm{C}-4^{\prime}\right), 76.2(\mathrm{CH}, \mathrm{C}-6), 76.8\left(\mathrm{CH}, \mathrm{C}-6^{\prime}\right), 82.7(\mathrm{CH}$, C-5), 130.0 (Cq, C-1), 130.4 (Cq, C-1'), 141.7 (CH, C-2), 142.7 (CH, C-2'), 167.0 (Cq, C-7'), 167.5 (Cq, C-7); HRFABMS $m / z$ calcd for $\mathrm{C}_{17} \mathrm{H}_{25} \mathrm{O}_{11} \mathrm{Na}(\mathrm{M}+\mathrm{Na})^{+} 427.1216$, found 427.1216 .

(+)-14 (4.2 mg, 22\%) was prepared from $(-)-\mathbf{1 2}(27.0 \mathrm{mg}, 0.048 \mathrm{mmol})$ : white powder; $[\alpha]_{\mathrm{D}}^{20}+27.5$ (c 0.095, EtOH); IR (film) $v_{\max } 3361(\mathrm{OH}), 1724(\mathrm{C}=\mathrm{O}), 1657(\mathrm{C}=\mathrm{C}) \mathrm{cm}^{-1} ;{ }^{1} \mathrm{H}-\mathrm{NMR}$ (acetone- $d_{6}, 600 \mathrm{MHz}$, ppm) $\delta 3.48$ (3H, s, 6'-OMe), 3.73 (3H, s, COOMe), 3.76 (3H, s, COOMe), 3.88 (1H, ddd, $J=9.7,5.0$, $2.4 \mathrm{~Hz}, \mathrm{H}-4), 3.94\left(1 \mathrm{H}, \mathrm{br} \mathrm{dd}, J=10.0,4.7 \mathrm{~Hz}, \mathrm{H}-4^{\prime}\right), 4.04(1 \mathrm{H}, \mathrm{ddd}, J=10.5,5.3,5.0 \mathrm{~Hz}, \mathrm{H}-3), 4.18(1 \mathrm{H}, \mathrm{d}$, $J=4.7 \mathrm{~Hz}, \mathrm{H}-5), 4.22\left(1 \mathrm{H}, \mathrm{br} \mathrm{d}, J=2.9 \mathrm{~Hz}, \mathrm{H}-6^{\prime}\right), 4.25(1 \mathrm{H}, \mathrm{d}, J=7.3 \mathrm{~Hz},-\mathrm{OH}), 4.35(1 \mathrm{H}, \mathrm{d}, J=10.7 \mathrm{~Hz}$, $-\mathrm{OH}), 4.40(1 \mathrm{H}, \mathrm{d}, J=3.2 \mathrm{~Hz}, \mathrm{H}-6), 4.42\left(1 \mathrm{H}, \mathrm{br} \mathrm{ddd}, J=7.3,3.5,3.2 \mathrm{~Hz}, \mathrm{H}-3^{\prime}\right), 4.47(1 \mathrm{H}, \mathrm{ddd}, J=5.6,3.8$, $\left.3.5 \mathrm{~Hz}, \mathrm{H}-5^{\prime}\right), 4.67(1 \mathrm{H}, \mathrm{d}, J=3.8 \mathrm{~Hz},-\mathrm{OH}) 6.73\left(1 \mathrm{H}, \mathrm{br} \mathrm{d}, J=2.9 \mathrm{~Hz}, \mathrm{H}-2^{\prime}\right), 6.87(1 \mathrm{H}, \mathrm{d}, J=4.7 \mathrm{~Hz}, \mathrm{H}-2)$; ${ }^{13} \mathrm{C}-\mathrm{NMR}$ (acetone- $\left.d_{6}, 150 \mathrm{MHz}, \mathrm{ppm}\right) \delta 52.1\left(2 \times \mathrm{CH}_{3}, \mathrm{C} 8, \mathrm{C}^{\prime}\right), 58.8\left(\mathrm{CH}_{3}, 6^{\prime}-\mathrm{OMe}\right), 66.3(\mathrm{CH}, \mathrm{C}-3)$, $66.7\left(\mathrm{CH}, \mathrm{C}-3^{\prime}\right), 67.2(\mathrm{CH}, \mathrm{C}-4), 69.6\left(\mathrm{CH}, \mathrm{C}-5^{\prime}\right), 70.3\left(\mathrm{CH}, \mathrm{C}-4^{\prime}\right), 76.0(\mathrm{CH}, \mathrm{C}-6), 76.8\left(\mathrm{CH}, \mathrm{C}-6^{\prime}\right), 81.2(\mathrm{CH}$, C-5), $130.4\left(\mathrm{Cq}, \mathrm{C}-1^{\prime}\right), 130.5$ (Cq, C-1), $141.3(\mathrm{CH}, \mathrm{C}-2), 141.5\left(\mathrm{CH}, \mathrm{C}-2^{\prime}\right), 167.0$ (Cq, C-7'), 167.5 (Cq, C-7); HRFABMS $\mathrm{m} / z$ calcd for $\mathrm{C}_{17} \mathrm{H}_{25} \mathrm{O}_{11} \mathrm{Na}(\mathrm{M}+\mathrm{Na})^{+} 427.1216$, found 427.1216.

(-)-6 (8.4 mg, 58\%) was prepared from (-)-13 $(20.2 \mathrm{mg}, 0.036 \mathrm{mmol})$ : white powder; $[\alpha]_{\mathrm{D}}^{20}-61.5$ (c 0.22, EtOH); IR (film) $v_{\max } 3392(\mathrm{OH}), 1718(\mathrm{C}=\mathrm{O}), 1653(\mathrm{C}=\mathrm{C}) \mathrm{cm}^{-1} ;{ }^{1} \mathrm{H}-\mathrm{NMR}$ (acetone- $d_{6}, 600 \mathrm{MHz}$, ppm) $\delta 3.47$ (3H, s, 6'-OMe), 3.73 (1H, overlapped, $\left.\mathrm{H}^{\prime} 5^{\prime}\right) 3.74$ (3H, s, COOMe), 3.80 (3H, s, COOMe), $3.94\left(1 \mathrm{H}, \mathrm{dd}, J=5.0,1.8 \mathrm{~Hz}, \mathrm{H}-4^{\prime}\right), 4.03\left(1 \mathrm{H}, \mathrm{br} \mathrm{s}, \mathrm{H}-4^{\prime}\right), 4.12(1 \mathrm{H}, \mathrm{br} \mathrm{dd}, J=5.0,4.7 \mathrm{~Hz}, \mathrm{H}-3), 4.21(1 \mathrm{H}$, overlapped, $\left.\mathrm{H}-3^{\prime}\right), 4.22(1 \mathrm{H}, \mathrm{dd}, J=3.0,2.3 \mathrm{~Hz}, \mathrm{H}-5), 4.33(1 \mathrm{H}, \mathrm{d}, J=3.2 \mathrm{~Hz}, \mathrm{H}-6), 4.51(1 \mathrm{H}, \mathrm{d}, J=4.1 \mathrm{~Hz}$, H-6'), $6.69\left(1 \mathrm{H}, \mathrm{d}, J=1.2 \mathrm{~Hz}, \mathrm{H}-2^{\prime}\right), 6.87(1 \mathrm{H}, \mathrm{d}, J=4.7 \mathrm{~Hz}, \mathrm{H}-2) ;{ }^{13} \mathrm{C}-\mathrm{NMR}$ (acetone- $d_{6}, 150 \mathrm{MHz}$, ppm) $\delta 52.1\left(\mathrm{CH}_{3}, \mathrm{C}-8\right), 52.4\left(\mathrm{CH}_{3}, \mathrm{C}-8^{\prime}\right), 58.6\left(\mathrm{CH}_{3}, 6^{\prime}-\mathrm{OMe}\right), 66.0(\mathrm{CH}, \mathrm{C}-3), 68.0(\mathrm{CH}, \mathrm{C}-4), 69.2(\mathrm{CH}$, C-3'), $70.5\left(\mathrm{CH}, \mathrm{C}-5^{\prime}\right), 72.4\left(\mathrm{CH}, \mathrm{C}-4^{\prime}\right), 76.2(\mathrm{CH}, \mathrm{C}-6), 76.8\left(\mathrm{CH}, \mathrm{C}-6^{\prime}\right), 82.7(\mathrm{CH}, \mathrm{C}-5), 130.1$ (Cq, C-1), 
130.5 (Cq, C1'), 141.7 (CH, C-2), 142.6 (CH, C-2'), 167.0 (Cq, C-7'), 167.5 (Cq, C-7); HRFABMS m/z calcd for $\mathrm{C}_{17} \mathrm{H}_{25} \mathrm{O}_{11}(\mathrm{M}+\mathrm{H})^{+}$405.1397, found 405.1399 .

$(-)-14(11.1 \mathrm{mg}, 40 \%)$ was prepared from $(+)-\mathbf{1 2}(38.4 \mathrm{mg}, 0.068 \mathrm{mmol})$ : white powder; $[\alpha]_{\mathrm{D}}^{20}-27.6$ (c 0.13, EtOH); IR (film) $v_{\max } 3415(\mathrm{OH}), 1720(\mathrm{C}=\mathrm{O}), 1655(\mathrm{C}=\mathrm{C}) \mathrm{cm}^{-1},{ }^{1} \mathrm{H}-\mathrm{NMR}$ (acetone- $d_{6}, 600 \mathrm{MHz}$, ppm) $\delta 3.50\left(3 \mathrm{H}, \mathrm{s}, 6^{\prime}-\mathrm{OMe}\right), 3.74(3 \mathrm{H}, \mathrm{s}, \mathrm{COOMe}), 3.78(3 \mathrm{H}, \mathrm{s}, \mathrm{COOMe}), 3.92(1 \mathrm{H}, \mathrm{dd}, J=5.0,2.4 \mathrm{~Hz}$, $\mathrm{H}-4), 3.96\left(1 \mathrm{H}, \mathrm{br} \mathrm{dd}, J=5.0,4.7 \mathrm{~Hz}, \mathrm{H}-4^{\prime}\right), 4.08(1 \mathrm{H}, \mathrm{dd}, J=5.0,4.7 \mathrm{~Hz}, \mathrm{H}-3), 4.15(1 \mathrm{H}, \mathrm{dd}, J=2.9$, $2.7 \mathrm{~Hz}, \mathrm{H}-5), 4.22\left(1 \mathrm{H}, \mathrm{d}, J=2.9 \mathrm{~Hz}, \mathrm{H}-6^{\prime}\right), 4.41(1 \mathrm{H}, \mathrm{d}, J=3.2 \mathrm{~Hz}, \mathrm{H}-6), 4.43(1 \mathrm{H}, \mathrm{br} \mathrm{dd}, J=3.3,2.9 \mathrm{~Hz}$, H-3'), $4.47\left(1 \mathrm{H}, \mathrm{dd}, J=5.6,3.2 \mathrm{~Hz}, \mathrm{H}-5^{\prime}\right), 6.75\left(1 \mathrm{H}, \mathrm{d}, J=2.6 \mathrm{~Hz}, \mathrm{H}-2^{\prime}\right), 6.88(1 \mathrm{H}, \mathrm{d}, J=4.7 \mathrm{~Hz}, \mathrm{H}-2)$; ${ }^{13} \mathrm{C}-\mathrm{NMR}$ (acetone- $\left.d_{6}, 150 \mathrm{MHz}, \mathrm{ppm}\right) \delta 52.2\left(\mathrm{CH}_{3}, \mathrm{C}-8\right), 52.3\left(\mathrm{CH}_{3}, \mathrm{C}-8^{\prime}\right), 58.8\left(\mathrm{CH}_{3}, 6^{\prime}-\mathrm{OMe}\right), 66.1(\mathrm{CH}$, C-3), $66.5\left(\mathrm{CH}, \mathrm{C}-3^{\prime}\right), 67.1(\mathrm{CH}, \mathrm{C}-4), 69.2\left(\mathrm{CH}, \mathrm{C}-5^{\prime}\right), 70.0\left(\mathrm{CH}, \mathrm{C}-4^{\prime}\right), 76.0(\mathrm{CH}, \mathrm{C}-6), 76.6\left(\mathrm{CH}, \mathrm{C}-6^{\prime}\right)$, 80.9 (CH, C-5), 130.3 (Cq, C-1'), 130.4 (Cq, C-1), 141.4 (CH, C-2), 141.7 (CH-C-2'), 167.2 (Cq, C-7'), 167.6 (Cq, C-7); HRFABMS m/z calcd for $\mathrm{C}_{17} \mathrm{H}_{25} \mathrm{O}_{11}(\mathrm{M}+\mathrm{H})^{+} 405.1397$, found 405.1391.

(-)-7 (6.2 mg, 54\%) was prepared from (+)-17 (16.1 mg, $0.029 \mathrm{mmol})$ : oil; $[\alpha]_{\mathrm{D}}^{20}-10.5(c 0.10, \mathrm{EtOH})$; IR (film) $v_{\max } 3355(\mathrm{OH}), 1717(\mathrm{C}=\mathrm{O}), 1652(\mathrm{C}=\mathrm{C}) \mathrm{cm}^{-1},{ }^{1} \mathrm{H}-\mathrm{NMR}$ (acetone- $\left.d_{6}, 400 \mathrm{MHz}, \mathrm{ppm}\right) \delta 3.47$ ( $\left.3 \mathrm{H}, \mathrm{s}, 6^{\prime}-\mathrm{OMe}\right), 3.77(3 \mathrm{H}, \mathrm{s}, \mathrm{COOMe}), 3.79(3 \mathrm{H}, \mathrm{s}, \mathrm{COOMe}), 3.82-3.86\left(1 \mathrm{H}, \mathrm{m}, \mathrm{H}-5^{\prime}\right), 3.88-4.04(2 \mathrm{H}, \mathrm{m}$, $\mathrm{OH}, \mathrm{OH}), 3.98-4.04\left(1 \mathrm{H}, \mathrm{m}, \mathrm{H}-4^{\prime}\right), 4.09(1 \mathrm{H}, \mathrm{br} \mathrm{d}, J=2.2 \mathrm{~Hz}, \mathrm{H}-5), 4.18-4.28\left(3 \mathrm{H}, \mathrm{m}, \mathrm{OH}, \mathrm{H}-3^{\prime}, \mathrm{H}-3\right)$, $4.32(1 \mathrm{H}, \mathrm{d}, J=3.7 \mathrm{~Hz}, \mathrm{H}-6), 4.43-4.49(1 \mathrm{H}, \mathrm{m}, \mathrm{H}-4), 4.67\left(1 \mathrm{H}, \mathrm{d}, J=3.7 \mathrm{~Hz}, \mathrm{H}-6^{\prime}\right), 4.66-4.74(1 \mathrm{H}, \mathrm{br}$, $\mathrm{OH}), 6.73(1 \mathrm{H}, \mathrm{d}, J=2.2 \mathrm{~Hz}, \mathrm{H}-2), 6.82\left(1 \mathrm{H}, \mathrm{d}, J=2.0 \mathrm{~Hz}, \mathrm{H}-2^{\prime}\right) ;{ }^{13} \mathrm{C}-\mathrm{NMR}$ (acetone- $d_{6}, 100 \mathrm{MHz}, \mathrm{ppm}$ ) $\delta 51.6\left(\mathrm{CH}_{3}, \mathrm{C}-8\right), 51.7\left(\mathrm{CH}_{3}, \mathrm{C}-8^{\prime}\right), 60.9\left(\mathrm{CH}_{3}, 6^{\prime}-\mathrm{OMe}\right), 68.6(\mathrm{CH}, \mathrm{C}-3), 68.9\left(\mathrm{CH}, \mathrm{C}-3^{\prime}\right), 69.1\left(\mathrm{CH}, \mathrm{C}-5^{\prime}\right)$, $70.2(\mathrm{CH}, \mathrm{C}-4), 72.2\left(\mathrm{CH}, \mathrm{C}-4^{\prime}\right), 75.0\left(\mathrm{CH}, \mathrm{C}-6^{\prime}\right), 75.4(\mathrm{CH}, \mathrm{C}-6), 79.6(\mathrm{CH}, \mathrm{C}-5), 129.5(\mathrm{CH}, \mathrm{C}-1), 129.7(\mathrm{CH}$, $\left.\mathrm{C}-1^{\prime}\right), 141.4(\mathrm{CH}, \mathrm{C}-2), 142.4\left(\mathrm{CH}, \mathrm{C}-2^{\prime}\right), 165.9$ (Cq, C-7), $166.4\left(\mathrm{Cq}, \mathrm{C}-7^{\prime}\right)$; HREIMS $\mathrm{m} / z$ calcd for $\mathrm{C}_{17} \mathrm{H}_{25} \mathrm{O}_{11}$ $(\mathrm{M}+\mathrm{H})^{+}$405.1397, found 405.1395.

(-)-18 (5.0 mg, 41\%) was prepared from (-)-16 (17.0 mg, 0.030 mmol): oil; $R_{f}=0.16\left(\mathrm{MeOH}: \mathrm{CH}_{2} \mathrm{Cl}_{2}\right.$ $=1: 9 \mathrm{v} / \mathrm{v}) ;[\alpha]_{\mathrm{D}}^{20}-21.6\left(\right.$ c 0.275, EtOH); IR (film) $v_{\max } 3357(\mathrm{OH}), 1718(\mathrm{C}=\mathrm{O}), 1657(\mathrm{C}=\mathrm{C}) \mathrm{cm}^{-1} ;{ }^{1} \mathrm{H}-\mathrm{NMR}$ (acetone- $\left.d_{6}, 400 \mathrm{MHz}, \mathrm{ppm}\right) \delta 3.31(1 \mathrm{H}, \mathrm{d}, J=5.3 \mathrm{~Hz},-\mathrm{OH}), 3.49\left(3 \mathrm{H}, \mathrm{s}, 6^{\prime}-\mathrm{OMe}\right), 3.70-3.78\left(1 \mathrm{H}, \mathrm{m}, \mathrm{H}-4^{\prime}\right)$, $3.777(3 \mathrm{H}, \mathrm{s}, \mathrm{COOMe}), 3.779(3 \mathrm{H}, \mathrm{s}, \mathrm{COOMe}), 3.82-3.88(2 \mathrm{H}, \mathrm{m},-\mathrm{OH},-\mathrm{OH}), 3.99(1 \mathrm{H}, \mathrm{dd}, J=3.7,2.2 \mathrm{~Hz}$, $\mathrm{H}-5), 4.07(1 \mathrm{H}, \mathrm{d}, J=7.0 \mathrm{~Hz},-\mathrm{OH}), 4.15(1 \mathrm{H}, \mathrm{d}, J=8.0 \mathrm{~Hz},-\mathrm{OH}), 4.20-4.28$ (2H, overlapped, H-5', H-3), 4.32-4.40 (3H, overlapped, H-6, H-6', H-3'), 4.42-4.48 (1H, m, H-4), $4.56(1 \mathrm{H}, \mathrm{d}, J=3.3 \mathrm{~Hz}, \mathrm{OH}) 6.74$ $(1 \mathrm{H}, \mathrm{dd}, J=2.4,1.4 \mathrm{~Hz}, \mathrm{H}-2), 6.77\left(1 \mathrm{H}, \mathrm{d}, J=3.3 \mathrm{~Hz}, \mathrm{H}-2^{\prime}\right) ;{ }^{13} \mathrm{C}-\mathrm{NMR}$ (acetone- $\left.d_{6}, 100 \mathrm{MHz}, \mathrm{ppm}\right) \delta$ $51.56\left(\mathrm{CH}_{3}, \mathrm{C}-8\right), 51.61\left(\mathrm{CH}_{3}, \mathrm{C}-8^{\prime}\right), 61.1\left(\mathrm{CH}_{3}, 6^{\prime}-\mathrm{OMe}\right), 65.9\left(\mathrm{CH}_{2}, \mathrm{C}-3^{\prime}\right), 69.1\left(\mathrm{CH}_{2}, \mathrm{C}-3\right), 70.3\left(\mathrm{CH}_{2}\right.$, $\mathrm{C}-4), 70.4\left(\mathrm{CH}_{2}, \mathrm{C}-4^{\prime}\right), 71.0\left(\mathrm{CH}_{2}, \mathrm{C}-5^{\prime}\right), 75.5\left(\mathrm{CH}_{2}, \mathrm{C}-6\right), 77.7\left(\mathrm{CH}, \mathrm{C}-6^{\prime}\right), 79.4(\mathrm{CH}, \mathrm{C}-5), 129.2(\mathrm{CH}, \mathrm{C}-1)$, $131.8\left(\mathrm{CH}, \mathrm{C}-1^{\prime}\right), 139.1$ (CH, C-2'), 141.8 (CH, C-2), 165.8 (Cq, C-7), 166.8 (Cq, C-7'); HREIMS m/z calcd for $\mathrm{C}_{17} \mathrm{H}_{25} \mathrm{O}_{11}(\mathrm{M}+\mathrm{H})^{+}$405.1397, found 405.1399.

(+)-7 (6.8 mg, 52\%) was prepared from (-)-17 (20.1 mg, $0.036 \mathrm{mmol})$ : oil; $[\alpha]_{\mathrm{D}}^{20}+11.4(c 0.11, \mathrm{EtOH}) ;$ IR (film) $v_{\max } 3359(\mathrm{OH}), 1717(\mathrm{C}=\mathrm{O}), 1652(\mathrm{C}=\mathrm{C}) \mathrm{cm}^{-1} ;{ }^{1} \mathrm{H}-\mathrm{NMR}$ (acetone- $\left.d_{6}, 400 \mathrm{MHz}, \mathrm{ppm}\right) \delta 3.47$ $\left(3 \mathrm{H}, \mathrm{s}, 6^{\prime}-\mathrm{OMe}\right), 3.77(3 \mathrm{H}, \mathrm{s}, \mathrm{COOMe}), 3.79(3 \mathrm{H}, \mathrm{s}, \mathrm{COOMe}), 3.84\left(1 \mathrm{H}, \mathrm{ddd}, J=8.2,4.1,2.2 \mathrm{~Hz}, \mathrm{H}-5^{\prime}\right)$, $3.89(1 \mathrm{H}, \mathrm{d}, J=7.4 \mathrm{~Hz},-\mathrm{OH}), 3.94(1 \mathrm{H}, \mathrm{d}, J=9.7 \mathrm{~Hz}, \mathrm{OH}), 4.00(1 \mathrm{H}, \mathrm{d}, J=9.8 \mathrm{~Hz},-\mathrm{OH}), 3.98-4.04$ $\left(1 \mathrm{H}, \mathrm{m}, \mathrm{H}-4^{\prime}\right), 4.09(1 \mathrm{H}, \mathrm{dd}, J=3.8,2.3 \mathrm{~Hz}, \mathrm{H}-5), 4.19(1 \mathrm{H}, \mathrm{d}, J=8.8 \mathrm{~Hz},-\mathrm{OH}), 4.22-4.28\left(2 \mathrm{H}, \mathrm{m}, \mathrm{H}-3^{\prime}\right.$ and $\mathrm{H}-3), 4.32(1 \mathrm{H}, \mathrm{d}, J=4.0 \mathrm{~Hz}, \mathrm{H}-6), 4.43-4.49(1 \mathrm{H}, \mathrm{m}, \mathrm{H}-4), 4.68(1 \mathrm{H}, \mathrm{d}, J=8.3 \mathrm{~Hz},-\mathrm{OH}), 4.67(1 \mathrm{H}$, $\left.\mathrm{d}, J=4.1 \mathrm{~Hz}, \mathrm{H}-6^{\prime}\right), 6.73(1 \mathrm{H}, \mathrm{dd}, J=2.6,4.3 \mathrm{~Hz}, \mathrm{H}-2), 6.83\left(1 \mathrm{H}, \mathrm{dd}, J=2.5,1.3 \mathrm{~Hz}, \mathrm{H}-2^{\prime}\right) ;{ }^{13} \mathrm{C}-\mathrm{NMR}$ (acetone- $\left.d_{6}, 100 \mathrm{MHz}, \mathrm{ppm}\right) \delta 51.6\left(\mathrm{CH}_{3}, \mathrm{C}-8\right), 51.7\left(\mathrm{CH}_{3}, \mathrm{C}-8^{\prime}\right), 60.9\left(\mathrm{CH}_{3}, 6^{\prime}-\mathrm{OMe}\right), 68.6(\mathrm{CH}, \mathrm{C}-3)$, $68.9\left(\mathrm{CH}, \mathrm{C}-3^{\prime}\right), 69.1\left(\mathrm{CH}, \mathrm{C}-5^{\prime}\right), 70.3(\mathrm{CH}, \mathrm{C}-4), 72.2\left(\mathrm{CH}, \mathrm{C}-4^{\prime}\right), 75.0\left(\mathrm{CH}, \mathrm{C}-6^{\prime}\right), 75.4(\mathrm{CH}, \mathrm{C}-6), 79.6(\mathrm{CH}$, C-5), 129.5 (Cq, C-1), 129.7 (Cq, C-1'), $141.3(\mathrm{CH}, \mathrm{C}-2), 142.4$ (CH, C-2'), 165.9 (Cq, C-7), 166.4 (Cq, C-7'); HREIMS $\mathrm{m} / z$ calcd for $\mathrm{C}_{17} \mathrm{H}_{24} \mathrm{O}_{11}(\mathrm{M})^{+} 404.1319$, found 404.1315.

(+)-18 (7.1 mg, 62\%) was prepared from (+)-16 (16.1 mg, $0.029 \mathrm{mmol})$ : oil; $[\alpha]_{\mathrm{D}}^{20}+24.3(c 0.36$, EtOH); IR (liquid film) $v_{\max } 3361(\mathrm{OH}), 1718(\mathrm{C}=\mathrm{O}), 1655(\mathrm{C}=\mathrm{C}) \mathrm{cm}^{-1},{ }^{1} \mathrm{H}-\mathrm{NMR}$ (acetone- $d_{6}, 400 \mathrm{MHz}$, ppm) $\delta 3.31(1 \mathrm{H}, \mathrm{d}, J=5.1 \mathrm{~Hz},-\mathrm{OH}), 3.49\left(3 \mathrm{H}, \mathrm{s}, 6^{\prime}-\mathrm{OMe}\right), 3.70-3.78\left(1 \mathrm{H}, \mathrm{m}, \mathrm{H}-4^{\prime}\right), 3.776(3 \mathrm{H}, \mathrm{s}, \mathrm{COOMe})$, $3.778(3 \mathrm{H}, \mathrm{s}, \mathrm{COOMe}), 3.86(1 \mathrm{H}, \mathrm{br} \mathrm{d}, J=9.5 \mathrm{~Hz},-\mathrm{OH}), 3.99(1 \mathrm{H}, \mathrm{dd}, J=3.7,2.0 \mathrm{~Hz}, \mathrm{H}-5), 4.07(1 \mathrm{H}, \mathrm{br} \mathrm{s}$, $-\mathrm{OH}), 4.14(1 \mathrm{H}, \mathrm{br} \mathrm{d}, J=8.2 \mathrm{~Hz},-\mathrm{OH}), 4.20-4.28\left(2 \mathrm{H}\right.$, overlapped, $\left.\mathrm{H}-5^{\prime}, \mathrm{H}-3\right), 4.32-4.40$ (3H, overlapped, H-6, H-6', H-3'), 4.42-4.48 (1H, m, H-4), 4.55 (1H, br s, -OH) $6.74(1 \mathrm{H}, \mathrm{dd}, J=2.2,1.4 \mathrm{~Hz}, \mathrm{H}-2), 6.77(1 \mathrm{H}$, 
br d, $\left.J=33 \mathrm{~Hz}, \mathrm{H}-2^{\prime}\right) ;{ }^{13} \mathrm{C}-\mathrm{NMR}$ (acetone- $\left.d_{6}, 100 \mathrm{MHz}, \mathrm{ppm}\right) \delta 51.56\left(\mathrm{CH}_{3}, \mathrm{C}-8\right), 51.61\left(\mathrm{CH}_{3}, \mathrm{C}-8^{\prime}\right)$, $61.1\left(\mathrm{CH}_{3}, 6^{\prime}-\mathrm{OMe}\right), 65.9\left(\mathrm{CH}_{2}, \mathrm{C}-3^{\prime}\right), 69.1\left(\mathrm{CH}_{2}, \mathrm{C}-3\right), 70.4\left(2 \times \mathrm{CH}, \mathrm{C}-4, \mathrm{C}-4^{\prime}\right), 71.0\left(\mathrm{CH}, \mathrm{C}-5^{\prime}\right), 75.5(\mathrm{CH}$, C-6), $77.7\left(\mathrm{CH}, \mathrm{C}-6^{\prime}\right), 79.4(\mathrm{CH}, \mathrm{C}-5), 129.2(\mathrm{Cq}, \mathrm{C}-1), 131.8$ (Cq, C-1'), $139.1\left(\mathrm{CH}, \mathrm{C}-2^{\prime}\right), 141.8(\mathrm{CH}, \mathrm{C}-2)$, 165.8 (Cq, C-7), 166.8 (Cq, C-7'); HREIMS m/z calcd for $\mathrm{C}_{17} \mathrm{H}_{24} \mathrm{O}_{11}(\mathrm{M})^{+} 404.1319$, found 404.1317.

(-)-8 (10.3 mg, 45\%) was prepared from (-)-20 (31.8 mg, $0.056 \mathrm{mmol}):$ oil; $[\alpha]_{\mathrm{D}}^{20}-96.7$ (c 0.48 , $\mathrm{EtOH}) ; \mathrm{IR}\left(\right.$ film) $v_{\max } 3419(\mathrm{OH}), 1728(\mathrm{C}=\mathrm{O}), 1653(\mathrm{C}=\mathrm{C}) \mathrm{cm}^{-1} ;{ }^{1} \mathrm{H}-\mathrm{NMR}$ (acetone- $d_{6}, 600 \mathrm{MHz}, \mathrm{ppm}$ ) $\delta 3.32(3 \mathrm{H}, \mathrm{s}, 6-\mathrm{OMe}), 3.59-3.78\left(1 \mathrm{H}, \mathrm{m}, \mathrm{H}-5^{\prime}\right), 3.76(3 \mathrm{H}, \mathrm{s}, \mathrm{COOMe}), 3.81(3 \mathrm{H}, \mathrm{s}, \mathrm{COOMe}), 3.96-3.99(2 \mathrm{H}$, $\left.\mathrm{m}, \mathrm{H}-4, \mathrm{H}-4^{\prime}\right), 4.13(1 \mathrm{H}, \mathrm{br} \mathrm{t}, J=4.1 \mathrm{~Hz}, \mathrm{H}-3), 4.33(1 \mathrm{H}, \mathrm{dd}, J=4.1,1.8 \mathrm{~Hz}, \mathrm{H}-5), 4.54(1 \mathrm{H}, \mathrm{d}, J=4.1 \mathrm{~Hz}$, H-6), $4.58\left(1 \mathrm{H}, J=4.2 \mathrm{~Hz}, \mathrm{H}-6^{\prime}\right), 6.83\left(1 \mathrm{H}, \mathrm{dd}, J=2.3,1.5 \mathrm{~Hz}, \mathrm{H}-2^{\prime}\right), 6.85(1 \mathrm{H}, \mathrm{d}, J=4.1 \mathrm{~Hz}, \mathrm{H}-2)$; ${ }^{13} \mathrm{C}-\mathrm{NMR}$ (acetone- $\left.d_{6}, 150 \mathrm{MHz}, \mathrm{ppm}\right) \delta 52.1\left(\mathrm{CH}_{3}, \mathrm{COOMe}\right), 52.5\left(\mathrm{CH}_{3}, \mathrm{COOMe}\right), 59.0\left(\mathrm{CH}_{3},-\mathrm{OMe}\right)$, $66.7(\mathrm{CH}, \mathrm{C}-3), 67.8(\mathrm{CH}, \mathrm{C}-4), 69.1\left(\mathrm{CH}, \mathrm{C}-3^{\prime}\right), 69.7\left(\mathrm{CH}, \mathrm{C}-5^{\prime}\right), 72.3\left(\mathrm{CH}, \mathrm{C}-4^{\prime}\right), 73.4\left(\mathrm{CH}, \mathrm{C}-6^{\prime}\right), 76.5$ (CH, C-6), 80.6 (CH, C-5), 130.1 (Cq, C-1'), 130.9 (Cq, C-1), $141.7(\mathrm{CH}, \mathrm{C}-2), 143.3\left(\mathrm{CH}, \mathrm{C}-2^{\prime}\right), 167.4(\mathrm{Cq}$, C-7), 167.5 (Cq, C-7); HRMS $\mathrm{m} / z$ calcd for $\mathrm{C}_{17} \mathrm{H}_{25} \mathrm{O}_{11}(\mathrm{M}+\mathrm{H})^{+} 405.1397$, found 405.1390 .

(-)-21 (10.3 mg, 45\%) was prepared from (-)-20 (31.8 mg, $0.056 \mathrm{mmol})$ : oil; $[\alpha]_{\mathrm{D}}^{20}-215.4(c$ 0.35, EtOH); IR (film) $v_{\max } 3393(\mathrm{OH}), 1716(\mathrm{C}=\mathrm{O}), 1653(\mathrm{C}=\mathrm{C}) \mathrm{cm}^{-1} ;{ }^{1} \mathrm{H}-\mathrm{NMR}$ (acetone- $d_{6}, 600 \mathrm{MHz}, \mathrm{ppm}$ ) $\delta 3.35(3 \mathrm{H}, \mathrm{s}, 6-\mathrm{OMe}), 3.75\left(1 \mathrm{H}, \mathrm{dd}, J=6.7,3.5 \mathrm{~Hz}, \mathrm{H}-4^{\prime}\right), 3.77$ ( $\left.3 \mathrm{H}, \mathrm{s}, \mathrm{COOMe}\right), 3.780$ (3H, s, COOMe), $4.00(2 \mathrm{H}, \mathrm{dd}, J=4.7,2.0 \mathrm{~Hz}, \mathrm{H}-4), 4.08\left(1 \mathrm{H}, \mathrm{dd}, J=6.7,4.1 \mathrm{~Hz}, \mathrm{H}-5^{\prime}\right), 4.14(1 \mathrm{H}, \mathrm{dd}, J=4.7,4.1 \mathrm{~Hz}$, H-3), $4.28(1 \mathrm{H}, \mathrm{dd}, J=4.1,2,1 \mathrm{~Hz}, \mathrm{H}-5), 4.35\left(1 \mathrm{H}, \mathrm{d}, J=3.8 \mathrm{~Hz}, \mathrm{H}-6^{\prime}\right), 4.37\left(1 \mathrm{H}, \mathrm{t}, J=3.8 \mathrm{~Hz}, \mathrm{H}-3^{\prime}\right), 4.42$ $\left(1 \mathrm{H}, \mathrm{br} \mathrm{d}, J=4.1 \mathrm{~Hz}, \mathrm{H}-6^{\prime}\right), 4.35\left(1 \mathrm{H}, J=3.8 \mathrm{~Hz}, \mathrm{H}-6^{\prime}\right), 4.42(1 \mathrm{H}, \mathrm{d}, J=3.8 \mathrm{~Hz}, \mathrm{H}-6), 4.35(1 \mathrm{H}, J=3.8$ $\left.\mathrm{Hz}, \mathrm{H}-6^{\prime}\right), 4.64(1 \mathrm{H}, \mathrm{d}, J=7.1 \mathrm{~Hz},-\mathrm{OH}), 6.81\left(1 \mathrm{H}, \mathrm{d}, J=3.5 \mathrm{~Hz}, \mathrm{H}-2^{\prime}\right), 6.83(1 \mathrm{H}, \mathrm{d}, J=4.1 \mathrm{~Hz}, \mathrm{H}-2)$; ${ }^{13} \mathrm{C}-\mathrm{NMR}$ (acetone- $\left.d_{6}, 150 \mathrm{MHz}, \mathrm{ppm}\right) \delta 52.2\left(\mathrm{CH}_{3}, \mathrm{COOMe}\right), 52.4\left(\mathrm{CH}_{3}, \mathrm{COOMe}\right), 59.2\left(\mathrm{CH}_{3},-\mathrm{OMe}\right)$, $66.4\left(\mathrm{CH}, \mathrm{C}-3^{\prime}\right), 66.9(\mathrm{CH}, \mathrm{C}-3), 67.9(\mathrm{CH}, \mathrm{C}-4), 70.7\left(\mathrm{CH}, \mathrm{C}-4^{\prime}\right), 71.8\left(\mathrm{CH}, \mathrm{C}-5^{\prime}\right), 76.66\left(\mathrm{CH}, \mathrm{C}-6^{\prime}\right), 76.70$ $(\mathrm{CH}, \mathrm{C}-6), 81.1(\mathrm{CH}, \mathrm{C}-5), 130.8(\mathrm{Cq}, \mathrm{C}-1), 131.1\left(\mathrm{Cq}, \mathrm{C}-1^{\prime}\right), 141.1\left(\mathrm{CH}, \mathrm{C}-2^{\prime}\right), 141.5(\mathrm{CH}, \mathrm{C}-2), 167.6(\mathrm{Cq}$, C-7), $167.9\left(\mathrm{Cq}, \mathrm{C}-7^{\prime}\right)$; HRMS $m / z$ calcd for $\mathrm{C}_{17} \mathrm{H}_{25} \mathrm{O}_{11}(\mathrm{M}+\mathrm{H})^{+} 405.1397$, found 405.1393.

(+)-8 (10.5 mg, 33\%) was prepared from $(+)-20(44.6 \mathrm{mg}, 0.079 \mathrm{mmol}):$ oil; $[\alpha]_{\mathrm{D}}^{20}+86.9(c 0.43$, EtOH); IR (film) $v_{\max } 3383(\mathrm{OH}), 1716(\mathrm{C}=\mathrm{O}), 1652(\mathrm{C}=\mathrm{C}) \mathrm{cm}^{-1},{ }^{1} \mathrm{H}-\mathrm{NMR}$ (acetone- $d_{6}, 400 \mathrm{MHz}, \mathrm{ppm}$ ) $\delta 3.51(3 \mathrm{H}, \mathrm{s},-\mathrm{OMe}), 3.76$ (3H, s, COOMe), 3.80 (3H, s, COOMe), 3.95-4.00 (2H, m, H-4, H-4'), 4.10-4.14 $(2 \mathrm{H}, \mathrm{m}), 4.24-4.28(1 \mathrm{H}, \mathrm{m}), 4.32(1 \mathrm{H}, \mathrm{dd}, J=4.3,2.0 \mathrm{~Hz}, \mathrm{H}-5), 4.52(1 \mathrm{H}, \mathrm{d}, J=4.3 \mathrm{~Hz}, \mathrm{H}-6), 4.59(1 \mathrm{H}$, $\left.\mathrm{d}, J=4.3 \mathrm{~Hz}, \mathrm{H}-6^{\prime}\right), 6.81\left(1 \mathrm{H}, \mathrm{d}, J=1.6 \mathrm{~Hz}, \mathrm{H}-2^{\prime}\right), 6.84(1 \mathrm{H}, \mathrm{d}, J=4.3 \mathrm{~Hz}, \mathrm{H}-2) ;{ }^{13} \mathrm{C}-\mathrm{NMR}$ (acetone- $d_{6}$, $100 \mathrm{MHz}, \mathrm{ppm}) \delta 50.7,51.1,57.6,65.3,66.4,67.7,68.3,70.9,72.0,75.1,79.3,128.7,129.4,140.3,142.0$, 165.9, 166.1; HREIMS $m / z$ calcd for $\mathrm{C}_{17} \mathrm{H}_{25} \mathrm{O}_{11}(\mathrm{M}+\mathrm{H})^{+}$405.1397, found 405.1393.

(+)-21 (9.0 mg, 32\%) was prepared from (+)-19 (40.0 mg, $0.07 \mathrm{mmol})$ : oil; $[\alpha]_{\mathrm{D}}^{20}+211(c$ 0.095, EtOH); IR (film) $v_{\max } 3419(\mathrm{OH}), 1716(\mathrm{C}=\mathrm{O}), 1653(\mathrm{C}=\mathrm{C}) \mathrm{cm}^{-1} ;{ }^{1} \mathrm{H}-\mathrm{NMR}$ (acetone- $\left.d_{6}, 400 \mathrm{MHz}, \mathrm{ppm}\right) \delta$ $3.49(3 \mathrm{H}, \mathrm{s}, 6-\mathrm{OMe}), 3.76(3 \mathrm{H}, \mathrm{s}, \mathrm{COOMe}), 3.79(3 \mathrm{H}, \mathrm{s}, \mathrm{COOMe}), 3.83(1 \mathrm{H}, \mathrm{br} \mathrm{d}, J=7.8 \mathrm{~Hz}) 3.90-3.39(2 \mathrm{H}$, m), 4.04-4.14 (2H, m), 4.19-4.24 (1H, m), $4.28(1 \mathrm{H}, \mathrm{dd}, J=3.9,2.9 \mathrm{~Hz}), 4.36(1 \mathrm{H}, \mathrm{d}, J=4.1 \mathrm{~Hz}), 4.36-4.39$ $(1 \mathrm{H}, \mathrm{m}), 4.41\left(1 \mathrm{H}, \mathrm{d}, J=3.9 \mathrm{~Hz}, \mathrm{H}-6^{\prime}\right), 4.53-4.57(1 \mathrm{H}, \mathrm{m}), 6.80(1 \mathrm{H}, \mathrm{d}, J=3.3 \mathrm{~Hz}), 6.82(1 \mathrm{H}, \mathrm{d}, J=4.3 \mathrm{~Hz})$; ${ }^{13} \mathrm{C}-\mathrm{NMR}$ (acetone- $d_{6}, 100 \mathrm{MHz}, \mathrm{ppm}$ ) 52.2, 52.4, 59.2, 66.4, 66.9, 67.8, 70.7, 71.8, 76.6, 76.7, 81.1, 130.7, 131.1, 141.0, 141.1, 167.5, 167.9 HREIMS $m / z$ calcd for $\mathrm{C}_{17} \mathrm{H}_{25} \mathrm{O}_{11}(\mathrm{M})^{+} 405.1396$, found 405.1390.

(-)-24 (1.9 mg, 26\%) was prepared from (-)-22 (10.2 mg, $0.018 \mathrm{mmol})$ : oil; $[\alpha]_{\mathrm{D}}^{20}-20.0$ (c 0.05 , EtOH); IR (film) $v_{\max } 3403(\mathrm{OH}), 1700(\mathrm{C}=\mathrm{O}), 1653(\mathrm{C}=\mathrm{C}) \mathrm{cm}^{-1},{ }^{1} \mathrm{H}-\mathrm{NMR}$ (acetone- $d_{6}, 600 \mathrm{MHz}, \mathrm{ppm}$ ) $\delta 3.56(3 \mathrm{H}, \mathrm{s}, \mathrm{OMe}), 3.70\left(1 \mathrm{H}, \mathrm{dt}, J=7.0,4.4 \mathrm{~Hz}, \mathrm{H}-4^{\prime}\right), 3.72(1 \mathrm{H}, \mathrm{d}, J=10.2 \mathrm{~Hz},-\mathrm{OH}), 3.77(3 \mathrm{H}, \mathrm{s}$, COOMe), $3.78(3 \mathrm{H}, \mathrm{s}, \mathrm{COOMe}), 3.92(1 \mathrm{H}, \mathrm{d}, J=6.5 \mathrm{~Hz},-\mathrm{OH}), 3.94(1 \mathrm{H}, \mathrm{d}, J=7.9 \mathrm{~Hz},-\mathrm{OH}), 4.04(1 \mathrm{H}, \mathrm{dd}$, $J=3.8,2.1 \mathrm{~Hz}, \mathrm{H}-6), 4.10-4.14(1 \mathrm{H}, \mathrm{m}, \mathrm{H}-3), 4.14(1 \mathrm{H}, \mathrm{d}, J=7.1 \mathrm{~Hz}, \mathrm{OH}), 4.23(1 \mathrm{H}, \mathrm{br} \mathrm{dt}, J=7.9,4.4 \mathrm{~Hz}$, H-5'), $4.35\left(1 \mathrm{H}, \mathrm{br} \mathrm{dt}, J=7.0,4.1 \mathrm{~Hz}, \mathrm{H}-3^{\prime}\right), 4.38\left(1 \mathrm{H}, \mathrm{d}, J=3.8 \mathrm{~Hz}, 3^{\prime}-\mathrm{OH}\right), 4.40\left(1 \mathrm{H}, \mathrm{d}, J=4.7 \mathrm{~Hz}, \mathrm{H}-6^{\prime}\right)$, $4.53(1 \mathrm{H}, \mathrm{d}, J=3.8 \mathrm{~Hz}, \mathrm{H}-6), 6.70(1 \mathrm{H}, \mathrm{dd}, J=2.6,1.1 \mathrm{~Hz}, \mathrm{H}-2), 6.72\left(1 \mathrm{H}, \mathrm{dd}, J=4.1,0.9 \mathrm{~Hz}, \mathrm{H}-2^{\prime}\right)$; ${ }^{13} \mathrm{C}-\mathrm{NMR}$ (acetone- $\left.d_{6}, 150 \mathrm{MHz}, \mathrm{ppm}\right) 52.1\left(\mathrm{CH}_{3},-\mathrm{COOMe}\right), 52.2\left(\mathrm{CH}_{3},-\mathrm{COOMe}\right), 61.1\left(\mathrm{CH}_{3},-\mathrm{OMe}\right)$, $66.6\left(\mathrm{CH}, \mathrm{C}-3^{\prime}\right), 69.5(\mathrm{CH}, \mathrm{C}-3), 70.2(\mathrm{CH}, \mathrm{C}-4), 71.1\left(\mathrm{CH}, \mathrm{C}-4^{\prime}\right), 71.9\left(\mathrm{CH}, \mathrm{C}-5^{\prime}\right), 76.7(\mathrm{CH}, \mathrm{C}-6), 78.0(\mathrm{CH}$, C-6'), 79.0 (CH, C-5), 130.6 (Cq, C-1), 132.7 (Cq, C-1'), 139.3 (CH, C-2'), 141.8 (CH, C-2), 166.8 (Cq, C-7), 167.6 (Cq, C-7'); HREIMS $m / z$ calcd for $\mathrm{C}_{17} \mathrm{H}_{24} \mathrm{O}_{11} \mathrm{M}^{+} 404.1318$, found 404.1311. 
(-)-9 (2.8 mg, 43\%) was prepared from (+)-23 (9.1 mg, $0.016 \mathrm{mmol})$ : oil; $[\alpha]_{\mathrm{D}}^{20}-49.0(c 0.085$, $\left.\mathrm{CHCl}_{3}\right)$; IR (film) $v_{\max } 3420(\mathrm{OH}), 1719(\mathrm{C}=\mathrm{O}), 1655(\mathrm{C}=\mathrm{C}), 1507(\mathrm{C}=\mathrm{C}), 1458(\mathrm{C}=\mathrm{C}) \mathrm{cm}^{-1} ;{ }^{1} \mathrm{H}-\mathrm{NMR}$ $\left(\mathrm{CDCl}_{3}, 600 \mathrm{MHz}, \mathrm{ppm}\right) \delta 3.56$ (3H, s, OMe), 3.81-3.85 (2H, m, overlapped), 3.819 (3H, s, COOMe), $3.824(3 \mathrm{H}, \mathrm{s}, \mathrm{COOMe}), 3.93(1 \mathrm{H}, \mathrm{br} \mathrm{s},-\mathrm{OH}), 3.94(1 \mathrm{H}, \mathrm{d}, J=2.6 \mathrm{~Hz},-\mathrm{OH}), 4.02-4.04(1 \mathrm{H}, \mathrm{m}), 4.14-4.17$ $(1 \mathrm{H}, \mathrm{m}), 4.22-4.23(1 \mathrm{H}, \mathrm{m}), 4.25(1 \mathrm{H}, \mathrm{dd}, J=3.5,2.1 \mathrm{~Hz}), 4.35(1 \mathrm{H}, \mathrm{m}, \mathrm{OH}), 4.51(1 \mathrm{H}, \mathrm{d}, J=3.5 \mathrm{~Hz}), 4.63$ $(1 \mathrm{H}, \mathrm{d}, J=4.4 \mathrm{~Hz}), 6.88(1 \mathrm{H}, \mathrm{d}, J=4.1 \mathrm{~Hz}), 6.94(1 \mathrm{H}, \mathrm{dd}, J=3.2,0.9 \mathrm{~Hz}) ;{ }^{13} \mathrm{C}-\mathrm{NMR}\left(\mathrm{CDCl}_{3}, 150 \mathrm{MHz}\right.$, ppm) 52.3, 52.5, 59.2, 67.3, 67.8, 69.0, 69.2, 70.5, 73.4, 74.9, 78.7, 129.4, 129.9, 140.2, 141.3, 166.4, 166.7; HREIMS $m / z$ calcd for $\mathrm{C}_{17} \mathrm{H}_{22} \mathrm{O}_{10}\left(\mathrm{M}-\mathrm{H}_{2} \mathrm{O}\right)^{+} 386.1213$, found 386.1210 .

(+)-24 (5.3 mg, 38\%) was prepared from (+)-22 (14.1 mg, $0.023 \mathrm{mmol}):$ oil; $[\alpha]_{\mathrm{D}}^{20}+20.7($ c 0.29 , EtOH); IR (film) $v_{\max } 3400(\mathrm{OH}), 1702(\mathrm{C}=\mathrm{O}), 1652(\mathrm{C}=\mathrm{C}) \mathrm{cm}^{-1} ;{ }^{1} \mathrm{H}-\mathrm{NMR}$ (acetone- $\left.d_{6}, 400 \mathrm{MHz}, \mathrm{ppm}\right)$ $\delta 3.56(3 \mathrm{H}, \mathrm{s}, \mathrm{OMe}), 3.71\left(1 \mathrm{H}, \mathrm{dd}, J=7.4,4.1 \mathrm{~Hz}, \mathrm{H}-4^{\prime}\right), 3.77(3 \mathrm{H}, \mathrm{s}, \mathrm{COOMe}), 3.78$ (3H, s, COOMe), 4.07 $(1 \mathrm{H}, \mathrm{dd}, J=3.7,1.8 \mathrm{~Hz}, \mathrm{H}-6), 4.14(1 \mathrm{H}, \mathrm{br} \mathrm{s},-\mathrm{OH}), 4.18(1 \mathrm{H}, \mathrm{br} \mathrm{s},-\mathrm{OH}), 4.23(1 \mathrm{H}, \mathrm{dd}, J=7.4,4.8 \mathrm{~Hz}$, H-5'), $4.35\left(1 \mathrm{H}, \mathrm{brt}, J=4.1 \mathrm{~Hz}, \mathrm{H}-3^{\prime}\right), 4.40\left(1 \mathrm{H}, \mathrm{d}, J=4.8 \mathrm{~Hz}, \mathrm{H}-6^{\prime}\right), 4.53(1 \mathrm{H}, \mathrm{d}, J=3.7 \mathrm{~Hz}, \mathrm{H}-6), 6.70(1 \mathrm{H}$, $\mathrm{dd}, J=2.6,1.0 \mathrm{~Hz}, \mathrm{H}-2), 6.72\left(1 \mathrm{H}, \mathrm{br} \mathrm{d}, J=3.9 \mathrm{~Hz}, \mathrm{H}-2^{\prime}\right) ;{ }^{13} \mathrm{C}-\mathrm{NMR}$ (acetone- $\left.d_{6}, 100 \mathrm{MHz}, \mathrm{ppm}\right) 52.07$, $52.13,61.1,66.5,69.5,70.1,71.0,71.8,76.5,78.0,79.0,130.5,132.6,139.3,141.8,166.7,167.6$; HREIMS m/z calcd for $\mathrm{C}_{17} \mathrm{H}_{22} \mathrm{O}_{10}\left(\mathrm{M}-\mathrm{H}_{2} \mathrm{O}\right)^{+} 386.1213$, found 386.1209.

(+)-9 (5.5 mg, 73\%) was prepared from (-)-23 (10.7 mg, $0.019 \mathrm{mmol})$ : oil; $[\alpha]_{\mathrm{D}}^{20}+49.5($ c 0.17 , $\left.\mathrm{CHCl}_{3}\right)$; IR (film) $v_{\max } 3410(\mathrm{OH}), 1719(\mathrm{C}=\mathrm{O}), 1655(\mathrm{C}=\mathrm{C}), 1506(\mathrm{C}=\mathrm{C}), 1456(\mathrm{C}=\mathrm{C}) \mathrm{cm}^{-1} ;{ }_{1} \mathrm{H}-\mathrm{NMR}$ $\left(\mathrm{CDCl}_{3}, 400 \mathrm{MHz}, \mathrm{ppm}\right) \delta 3.58$ (3H, s, OMe), 3.78-3.84 (2H, m, overlapped), 3.82 (3H, s, COOMe), 3.83 (3H, s, COOMe), 3.90-3.96 (1H, m), 4.40-4.18 (1H, m), 4.12-4.18 (1H, m), 4.20-4.26 (1H, m), $4.29(1 \mathrm{H}$, $\mathrm{dd}, J=3.3,1.8 \mathrm{~Hz}), 4.44(1 \mathrm{H}, \mathrm{br} \mathrm{s}, \mathrm{OH}), 4.47(1 \mathrm{H}, \mathrm{d}, J=3.7 \mathrm{~Hz}), 4.63(1 \mathrm{H}, \mathrm{d}, J=4.1 \mathrm{~Hz}), 6.87(1 \mathrm{H}, \mathrm{d}$, $J=3.9 \mathrm{~Hz}), 6.93(1 \mathrm{H}, \mathrm{br} \mathrm{d}, J=2.9 \mathrm{~Hz},) ;{ }^{13} \mathrm{C}-\mathrm{NMR}\left(\mathrm{CDCl}_{3}, 100 \mathrm{MHz}, \mathrm{ppm}\right) 52.3,52.5,59.2,67.1,67.9$, $68.8,69.2,70.5,74.6,75.1,78.5,129.4,130.1,139.7,141.4,166.6,166.7$; HREIMS $m / z$ calcd for $\mathrm{C}_{17} \mathrm{H}_{25} \mathrm{O}_{11}$ $(\mathrm{M}+\mathrm{H})^{+}$405.1396, found 405.1395.

\subsection{Assays of Glycosidase Inhibitory Activity}

Assay of $\alpha$-Glucosidase Inhibitory Activity

The assay reaction mixture comprised $0.1 \mathrm{M}$ acetate buffer $(\mathrm{pH} 5.0,45 \mu \mathrm{L}), 20 \mathrm{mM}$ $p$-nitrophenyl- $\alpha$-D-glucopyranoside solution $(25 \mu \mathrm{L})$, and $\alpha$-glucosidase solution $(25 \mu \mathrm{L}$, stock solution of $1.0 \mathrm{mg} / \mathrm{mL}$ in $50 \mathrm{mM}$ Tris-HCl-buffer at $\mathrm{pH} 7.8$ diluted 20-fold with $10 \mathrm{mM}$ phosphate buffer at $\mathrm{pH}$ 7.0 ), with the test samples or DNJ ( $5 \mu \mathrm{L}$ solution, concentration range $0.1-20 \mathrm{mg} / \mathrm{mL}$ ). After $20 \mathrm{~min}$ incubation at $37^{\circ} \mathrm{C}$, the reaction was quenched by addition of $\mathrm{Na}_{2} \mathrm{CO}_{3}$ solution $(0.5 \mathrm{M}, 100 \mu \mathrm{L})$. The amount of liberated $p$-nitrophenol was measured colorimetrically at $400 \mathrm{~nm}$ (optical density at $400 \mathrm{~nm}$ : ODtest). Inhibition efficiencies (\%) were calculated as $100-100 \times($ ODtest - ODblank)/(control ODtest - control ODblank), and $\mathrm{IC}_{50}$ values (Table 1) were obtained from inhibition curves.

Assays of $\beta$-glucosidase, $\alpha$-mannosidase, $\beta$-mannosidase, and $\beta$-galactosidase inhibitory activities were carried out as above using $p$-nitrophenyl- $\beta$-D-glucopyranoside, $p$-nitrophenyl- $\alpha$-Dmannopyranoside, $p$-nitrophenyl- $\beta$-D-mannopyranoside, and $p$-nitrophenyl- $\beta$-D- galactopyranoside as substrates. The corresponding $\mathrm{IC}_{50}$ values are listed in Table 1.

*Isolation of positive control deoxynojirimycin: Dried leaves of Morus alba L. (0.5 kg) were cut finely and then extracted with hot water $(10 \mathrm{~L})$ for $2 \mathrm{~h}$. The extracted solution was chromatographed on an Amberlite CG-50 ( $\mathrm{H}^{+}$-form) column (6.5 mm inside diameter (i.d.) $\times 30 \mathrm{~cm}$ length). After washing the column with water and then $50 \% \mathrm{MeOH}$, the adsorbed material was eluted with $50 \% \mathrm{MeOH}-28 \%$ ammonia solution (9:1). The eluted fraction was concentrated in vacuo to give a basic fraction (5.0 g). This fraction was chromatographed on a Dowex 50W-X4 column (200-400 mesh, $5.0 \mathrm{~mm}$ i.d. $\times 20 \mathrm{~cm})$ pretreated with formic acid-ammonium formate buffer $(0.2 \mathrm{M}$ ammonia formate, adjusted to $\mathrm{pH}$ 5.7 with $1 \mathrm{M}$ formic acid), with stepwise elution $\left(\mathrm{H}_{2} \mathrm{O}, \mathrm{H}_{2} \mathrm{O}-28 \%\right.$ ammonia solution (99:1, 9:1)). The fraction $\left(\mathrm{H}_{2} \mathrm{O}-28 \%\right.$ ammonia solution (99:1)) was re-chromatographed on semi-preparative HPLC 
(column:Shodex $\mathrm{NH}_{2} \mathrm{P}\left(4.6 \mathrm{~mm}\right.$ i.d. $\times 250 \mathrm{~mm}$ ), solvent: $\mathrm{CH}_{3} \mathrm{CN}-\mathrm{H}_{2} \mathrm{O}(80: 20)$, flow rate: $1.0 \mathrm{~mL} / \mathrm{min}$, column temperature: ambient). 1-Deoxynojirimycin $(40 \mathrm{mg})$ was finally obtained.

\subsection{Docking Simulation}

The docking analysis was carried out using $\alpha$-glucosidase protein (PDB code 3A4A) using the Dock induced-fit function in Molecular Operating Environment (MOE) version 2018.0101 (Chemical Computing Group Inc., Quebec, Canada) to better understand the inhibitory mechanisms. $[18,19]$ The calculation of the binding affinity scoring function was performed with the amber 10:eht force field, triangle matcher as placement, and GBVI/WSA dG as the binding affinity scoring function [26]. In the protein preparation with respect to charged residues in the binding site, the Protonate three dimensional (3D) option in MOE was used to determine the ionization states and add hydrogens to the system [27]. The function of the Protonate 3D allows to assign ionization states and position hydrogens in a macromolecular structure given its 3D coordinates from the crystal structure. Hydrogen atoms are required for all atom molecular mechanics, dynamics, or electrostatic calculations. The addition of hydrogen atoms to a macromolecule is a non-trivial task; generally, one must determine the rotamers of $-\mathrm{SH}-\mathrm{OH}-\mathrm{CH}_{3}$ and $-\mathrm{NH}_{3}$ groups in cysteine (CYS), serine (SER), tyrosine (TYR), threonine(THR), methionine (MET), and lysine (LYS), the ionization states of acids and bases in arginine (ARG), aspartic acid (ASP), glutamic acid (GLU), LYS, histidine (HIS), the tautomers of imidazoles (HIS) and carboxylic acids (ASP, GLU), the protonation state of metal-ligand atoms CYS, HIS, ASP, GLU, etc., and the ionization state of metals.

Supplementary Materials: The following are available online at http://www.mdpi.com/1660-3397/18/4/221/s1. Modified preparation of anti-epoxide (-)-11, Synthesis of new compound (-)-15, Figure S1: ${ }^{1} \mathrm{H}-\mathrm{NMR}$ Spectrum of (-)-15, Figure S2: ${ }^{13} \mathrm{C}-\mathrm{NMR}$ Spectrum of (-)-15, Figure S3: ${ }^{1} \mathrm{H}-\mathrm{NMR}$ Spectrum of (+)-14, Figure S4: ${ }^{13} \mathrm{C}-\mathrm{NMR}$ Spectrum of $(+)-14$, Figure S5: ${ }^{1} \mathrm{H}-\mathrm{NMR}$ Spectrum of $(+)-12$, Figure S6: ${ }^{13} \mathrm{C}-\mathrm{NMR}$ Spectrum of $(+)-12$, Figure S7: ${ }^{1}$ H-NMR Spectrum of (-)-16, Figure S8: ${ }^{13} \mathrm{C}-\mathrm{NMR}$ Spectrum of (-)-16, Figure S9: ${ }^{1} \mathrm{H}-\mathrm{NMR}$ Spectrum of (+)-16, Figure S10: ${ }^{13} \mathrm{C}$-NMR Spectrum of (+)-16, Figure S11: ${ }^{1} \mathrm{H}-\mathrm{NMR}$ Spectrum of (-)-19, Figure S12: ${ }^{13} \mathrm{C}-\mathrm{NMR}$ Spectrum of (-)-19, Figure S13: ${ }^{1} \mathrm{H}-\mathrm{NMR}$ Spectrum of (+)-19, Figure S14: ${ }^{13} \mathrm{C}-\mathrm{NMR}$ Spectrum of (+)-19, Figure S15: ${ }^{1} \mathrm{H}-\mathrm{NMR}$ Spectrum of (-)-22, Figure S16: ${ }^{13} \mathrm{C}-\mathrm{NMR}$ Spectrum of (-)-22, Figure S17: ${ }^{1} \mathrm{H}-\mathrm{NMR}$ Spectrum of $(+)-22$, Figure S18: ${ }^{13} \mathrm{C}-\mathrm{NMR}$ Spectrum of $(+)-22$, Figure S19: ${ }^{1} \mathrm{H}-\mathrm{NMR}$ Spectrum of (+)-13, Figure S20: ${ }^{33} \mathrm{C}-\mathrm{NMR}$ Spectrum of $(+)-13$, Figure S21: ${ }^{1} \mathrm{H}-\mathrm{NMR}$ Spectrum of (-)-13, Figure S22: ${ }^{13} \mathrm{C}-\mathrm{NMR}$ Spectrum of (-)-13, Figure S23: ${ }^{1} \mathrm{H}-\mathrm{NMR}$ Spectrum of (+)-17, Figure S24: ${ }^{13} \mathrm{C}-\mathrm{NMR}$ Spectrum of $(+)-17$, Figure S25: ${ }^{1} \mathrm{H}-\mathrm{NMR}$ Spectrum of (-)-17, Figure S26: ${ }^{13} \mathrm{C}-\mathrm{NMR}$ Spectrum of (-)-17, Figure S27: ${ }^{1} \mathrm{H}-\mathrm{NMR}$ Spectrum of (-)-20, Figure S28: ${ }^{13} \mathrm{C}-\mathrm{NMR}$ Spectrum of (-)-20, Figure S29: ${ }^{1} \mathrm{H}$ - NMR Spectrum of (+)-20, Figure S30: ${ }^{13} \mathrm{C}-\mathrm{NMR}$ Spectrum of (+)-20, Figure S31: ${ }^{1} \mathrm{H}-\mathrm{NMR}$ Spectrum of (+)-23, Figure S32: ${ }^{13} \mathrm{C}-\mathrm{NMR}$ Spectrum of (+)-23, Figure S33: ${ }^{1} \mathrm{H}-\mathrm{NMR}$ Spectrum of (-)-23, Figure S34: ${ }^{13} \mathrm{C}-\mathrm{NMR}$ Spectrum of (-)-23, Figure S35: ${ }^{1} \mathrm{H}-\mathrm{NMR}$ Spectrum of (+)-6, Figure S36: ${ }^{13} \mathrm{C}-\mathrm{NMR}$ Spectrum of $(+)-6$, Figure S37: ${ }^{1} \mathrm{H}-\mathrm{NMR}$ Spectrum of (-)-6, Figure S38: ${ }^{13} \mathrm{C}-\mathrm{NMR}$ Spectrum of (-)-6, Figure S39: ${ }^{1} \mathrm{H}-\mathrm{NMR}$ Spectrum of (+)-14, Figure S40: ${ }^{13} \mathrm{C}-\mathrm{NMR}$ Spectrum of (+)-14, Figure S41: ${ }^{1} \mathrm{H}-\mathrm{NMR}$ Spectrum of (-)-14, Figure S42: ${ }^{13} \mathrm{C}-\mathrm{NMR}$ Spectrum of (-)-14, Figure S43: ${ }^{1} \mathrm{H}-\mathrm{NMR}$ Spectrum of (+)-7, Figure S44: ${ }^{13} \mathrm{C}-\mathrm{NMR}$ Spectrum of (+)-7, Figure S45: ${ }^{1} \mathrm{H}-\mathrm{NMR}$ Spectrum of (-)-7, Figure S46: ${ }^{13} \mathrm{C}-\mathrm{NMR}$ Spectrum of (-)-7, Figure S47: ${ }^{1} \mathrm{H}-\mathrm{NMR}$ Spectrum of (-)-18, Figure S48: ${ }^{13} \mathrm{C}-\mathrm{NMR}$ Spectrum of (-)-18, Figure S49: ${ }^{1} \mathrm{H}-\mathrm{NMR}$ Spectrum of (+)-18, Figure S50: ${ }^{13} \mathrm{C}-\mathrm{NMR}$ Spectrum of $(+)-18$, Figure S51: ${ }^{1}$ H-NMR Spectrum of (-)-8, Figure S52: ${ }^{13}$ C-NMR Spectrum of (-)-8, Figure S53: ${ }^{1} \mathrm{H}$ - NMR Spectrum of (+)-8, Figure S54: ${ }^{13} \mathrm{C}-\mathrm{NMR}$ Spectrum of (+)-8, Figure S55: ${ }^{1} \mathrm{H}$ - NMR Spectrum of (-)-21, Figure S56: ${ }^{13} \mathrm{C}-\mathrm{NMR}$ Spectrum of (-)-21, Figure S57: ${ }^{1} \mathrm{H}-\mathrm{NMR}$ Spectrum of $(+)-21$, Figure S58: ${ }^{13} \mathrm{C}-\mathrm{NMR}$ Spectrum of (+)-21, Figure S59: ${ }^{1} \mathrm{H}-\mathrm{NMR}$ Spectrum of (-)-24, Figure S60: ${ }^{13} \mathrm{C}-\mathrm{NMR}$ Spectrum of (-)-24, Figure S61: ${ }^{1} \mathrm{H}-\mathrm{NMR}$ Spectrum of (+)-24, Figure S62: ${ }^{13} \mathrm{C}$-NMR Spectrum of $(+)-24$, Figure S63: ${ }^{1} \mathrm{H}-\mathrm{NMR}$ Spectrum of (-)-9, Figure S64: ${ }^{13} \mathrm{C}-\mathrm{NMR}$ Spectrum of (-)-9, Figure S65: ${ }^{1} \mathrm{H}$ - NMR Spectrum of (+)-9, Figure S66: ${ }^{13} \mathrm{C}-\mathrm{NMR}$ Spectrum of (+)-9.

Author Contributions: Y.U. (Yoshihide Usami) conceived and designed the experiments; Y.U. (Yoshihide Usami), M.H., K.M., M.Y., C.N. and Y.S. performed the synthetic experiments; M.H., M.K., and M.S. performed glycosidase assays; Y.U. (Yoshihiro Uesawa) and J.N. performed in silico study; Y.U. (Yoshihide Usami), Y.U. (Yoshihiro Uesawa), J.N., H.Y., and S.H. wrote the manuscript. All authors have read and agreed to the published version of the manuscript.

Funding: Part of this work was financially supported by Special subsidies in Operation Coasts Subsidies for Private Universities from the Japanese government. 
Acknowledgments: The authors are grateful to Professors K. Minoura and M. Fujitake of Osaka University of Pharmaceutical Sciences for NMR and MS measurements, respectively. Ms. E. Yamada and Y. Mizobuchi of our laboratory are also appreciated for their experimental support. We would like to thank Editage (www.editage.com) for English language editing.

Conflicts of Interest: The authors declare no conflict of interest.

\section{References}

1. Yamada, T.; Iritani, M.; Ohishi, H.; Tanaka, K.; Doi, M.; Minoura, K.; Numata, A. Pericosines, antitumour metabolites from the sea hare-derived fungus Periconia byssoides. Structures and biological activities. Org. Biomol. Chem. 2007, 5, 3979-3986. [CrossRef]

2. Usami, Y. Synthesis of marine-drived carbasugar pericosines. In Studies in Natural Product Chemistry; Pergamon: Oxford, UK, 2014; Volume 41, pp. 287-319. [CrossRef]

3. Donohoe, T.J.; Blades, K.; Helliwell, M.; Warning, M.J.; Newcombe, N.J. The synthesis of (+)-pericosine B. Tetrahedron Lett. 1998, 39, 8755-8758. [CrossRef]

4. Boyd, D.R.; Sharma, N.D.; Acaru, C.A.; Malone, J.F.; O’Dowd, C.R.; Allen, C.C.R.; Stevenson, P.J. Chemoenzymatic Synthesis of carbasugars (+)-pericosines A-C from diverse aromatic cis-dihydrodiol precursors. Org. Lett. 2010, 12, 2206-2209. [CrossRef]

5. Tripathi, S.; Shaikh, A.C.; Chen, C. Facile carbohydrate-based stereocontrolled divergent synthesis of (+)-pericosines A and B. Org. Biomol. Chem. 2011, 9, 7306-7308. [CrossRef]

6. Reddy, Y.S.; Kadigachalam, P.; Basak, R.K.; Pal, A.P.J.; Vankar, Y.D. Total synthesis of (+)-pericosine B and $(+)$-pericosine $\mathrm{C}$ and their enantiomers by using the Baylis-Hillman reaction and ring-closing metathesis as key steps. Tetrahedron Lett. 2012, 53, 132-136. [CrossRef]

7. MuniRaju, C.; Rao, J.P.; Rao, B.V. Stereoselective synthesis of (+)-pericosine B and (+)-pericosine C using ring closing metathesis approach. Tetrahedron Asymmetry 2012, 23, 86-93. [CrossRef]

8. Li, L.-S.; Hou, D.-R. Diastereoselective vinylalumination for the synthesis of pericosine A, B and C. RSC Adv. 2014, 4, 91-97. [CrossRef]

9. Babu, D.C.; Rao, C.B.; Venkastesham, K.; Selvam, J.J.P.; Venkasteswarlu, Y. Toward synthesis of carbasugars (+)-gabosine C, (+)-COTC, (+)-pericosine B, and (+)-pericosine C. Carbohydr. Res. 2014, 388, $130-137$. [CrossRef]

10. Mizuki, K.; Iwahashi, K.; Murata, N.; Ikeda, M.; Nakai, N.; Yoneyama, H.; Harusawa, S.; Usami, Y. Synthesis of marine natural product (-)-pericosine E. Org. Lett. 2014, 16, 3760-3763. [CrossRef]

11. Usami, Y.; Mizuki, K.; Kawahata, R.; Shibano, M.; Sekine, A.; Yoneyama, H.; Harusawa, S. Synthesis of natural $O$-linked carba-disaccharides, (+)- and (-)-pericosine E, and their analogues as $\alpha$-glucosidase inhibitors. Mar. Drugs 2017, 15, 22. [CrossRef]

12. Usami, Y.; Ohsugi, M.; Mizuki, K.; Ichikawa, H.; Arimoto, M. Facile and efficient synthesis of naturally occurring carbasugars (+)-pericosines A and C. Org. Lett. 2009, 11, 2699-2701. [CrossRef]

13. Usami, Y.; Suzuki, K.; Mizuki, K.; Ichikawa, H.; Arimoto, M. Synthesis of (-)-pericosine B, antipode of cytotoxic marine natural product. Org. Biomol. Chem. 2009, 7, 315-318. [CrossRef]

14. Ogawa, S.; Kanto, M.; Suzuki, Y. Development and medical application of unsaturated carbaglycosylamine glycosidase inhibitors. Mini Rev. Med. Chem. 2007, 7, 679-691. [CrossRef] [PubMed]

15. Kumar, K.S.A.; Rathee, J.S.; Subramanian, M.; Chattopadhyay, S. Divergent synthesis of 4-epi-fagomine, 3,4-dihydroxypipecolic acid, and a dihydroxyindolizidine and their $\beta$-galactosidase inhibitory and immunomodulatoryactivities. J. Org. Chem. 2013, 78, 7406-7413. [CrossRef] [PubMed]

16. Dada, L.; Manzano, V.E.; Varela, O. Design and synthesis of 2-acetamido-2,3-dideoxythiodisaccharides via diastereoselective conjugate addition to sugar enone $\mathrm{O}$-acetyl oximes. galactosidase inhibition studies. Org. Lett. 2018, 20, 6225-6228. [CrossRef] [PubMed]

17. Front, S.; Gallienne, E.; Charollais-Thoenig, J.; Demotz, S.; Martin, O.R. N-Alkyl-, 1-C-slkyl-, and 5-C-Alkyl-1,5-dideoxy-1,5-imino-(L)-ribitols as galactosidase inhibitors. ChemMedChem 2016, 11, $133-141$. [CrossRef]

18. Govindaraj, R.G.; Manavalan, B.; Lee, G.; Choi, S. Molecular modeling-based evaluation of hTLR10 and identification of potential ligands in toll-like receptor signaling. PLoS ONE 2010, 5, e12713. [CrossRef] 
19. Yamamoto, K.; Miyake, H.; Kusunoki, M.; Osaki, S. Crystal structures of isomaltase from Saccharomyces cerevisiae and in complex with its competitive inhibitor maltose. FEBS J. 2010, 277, 4205-4214. [CrossRef]

20. Tang, H.; Zhao, D.; Xue, Z. Exploring the interaction between Salvia miltiorrhiza and $\alpha$-glucosidase: Insights from computational analysis and experimental studies. RSC Adv. 2018, 8, 24701-24710. [CrossRef]

21. Kalinowsky, L.; Weber, J.; Balasupramaniam, S.; Baumann, K.; Proschak, E. A Diverse Benchmark Based on 3D Matched Molecular Pairs for Validating Scoring Functions. ACS Omega 2018, 3, 5704-5714. [CrossRef]

22. Rivera-Chavez, J.; Gonzalez-Andrade, M.; Gonzalez Mdel, C.; Glenn, A.E.; Mata, R. Thielavins A, $\mathrm{J}$ and $\mathrm{K}: \alpha$-Glucosidase inhibitors from MEXU 27095, an endophytic fungus from Hintonia latiflora. Phytochemistry 2013, 94, 198-205. [CrossRef] [PubMed]

23. Murugesu, S.; Ibrahim, Z.; Ahmed, Q.U.; Yusoff, N.I.N.; Uzir, B.F.; Perumal, V.; Abas, F.; Saari, K.; El-Seedi, H.; Khatib, A. Characterization of $\alpha$-Glucosidase Inhibitors from Clinacanthus nutans Lindau Leaves by Gas Chromatography-Mass Spectrometry-Based Metabolomics and Molecular Docking Simulation. Molecules 2018, 23, 2402. [CrossRef] [PubMed]

24. Murugesu, S.; Ibrahim, Z.; Ahmed, Q.U.; Uzir, B.F.; Yusoff, N.I.N.; Perumal, V.; Abas, F.; Shaari, K.; Khatib, A. Identification of $\alpha$-glucosidase inhibitors from Clinacanthus nutans leaf extract using liquid chromatography-mass spectrometry-based metabolomics and protein-ligand interaction with molecular docking. J. Pharm. Anal. 2019, 9, 91-99. [CrossRef] [PubMed]

25. Gopalan, G.; Prabha, B.; Joe, A.; Reshmitha, T.R.; Sherin, D.R.; Abraham, B.; Sabu, M.; Manojkumar, T.K.; Radhakrishnan, K.V.; Nisha, P. Screening of Musa balbisiana Colla. seeds for antidiabetic properties and isolation of apiforol, a potential lead, with antidiabetic activity. J. Sci. Food Agric. 2019, 99, 2521-2529. [CrossRef] [PubMed]

26. Corbeil, C.R.; Williams, C.I.; Labute, P. Variability in docking success rates due to dataset preparation. J. Comput. Aided Mol. Des. 2012, 26, 775-786. [CrossRef]

27. Labute, P. Protonate3D: Assignment of ionization states and hydrogen coordinates to macromolecular structures. Proteins 2009, 75, 187-205. [CrossRef] 